
JOINT HIGHWAY RESEARCH PROJECT

\section{FHWA/IN/JHRP-94/4}

Final Report

AN EVALUATION OF THE STRATEGIC HIGHWAY RESEARCH PROJECT PACKING HANDBOOK

Kenneth P. Cox

Charles F. Scholer

Menashi D. Cohen 
Digitized by the Internet Archive in 2011 with funding from

LYRASIS members and Sloan Foundation; Indiana Department of Transportation 
Final Report

\title{
AN EVALUATION OF THE STRATEGIC HIGHWAY RESEARCH PROJECT PACKING HANDBOOK
}

\author{
by \\ Kenneth P. Cox \\ Charles F. Scholer \\ Menashi D. Cohen
}

Joint Highway Research Project

Project No.: C-36-65H

File No. 5-15-8

Prepared as Part of an Investigation

conducted by the

Joint Highway Research Project

Engineering Experiment Station

Purdue University

In Cooperation with the Indiana Department of Transportation

and the

U.S. Department of Transportation

Federal Highway Administration

The contents of this document reflect the views of the authors who are responsible for the facts and accuracy of the data presented herein. The contents do not necessarily reflect the official views of policies of the Federal Highway Administration. This document does not constitute a standard, specifications, or regulations.

School of Civil Engineering

Purdue University

West Lafayette, Indiana 47907

May 1994 
TECHNICAL REPORT STANDARO TITLE PAGE

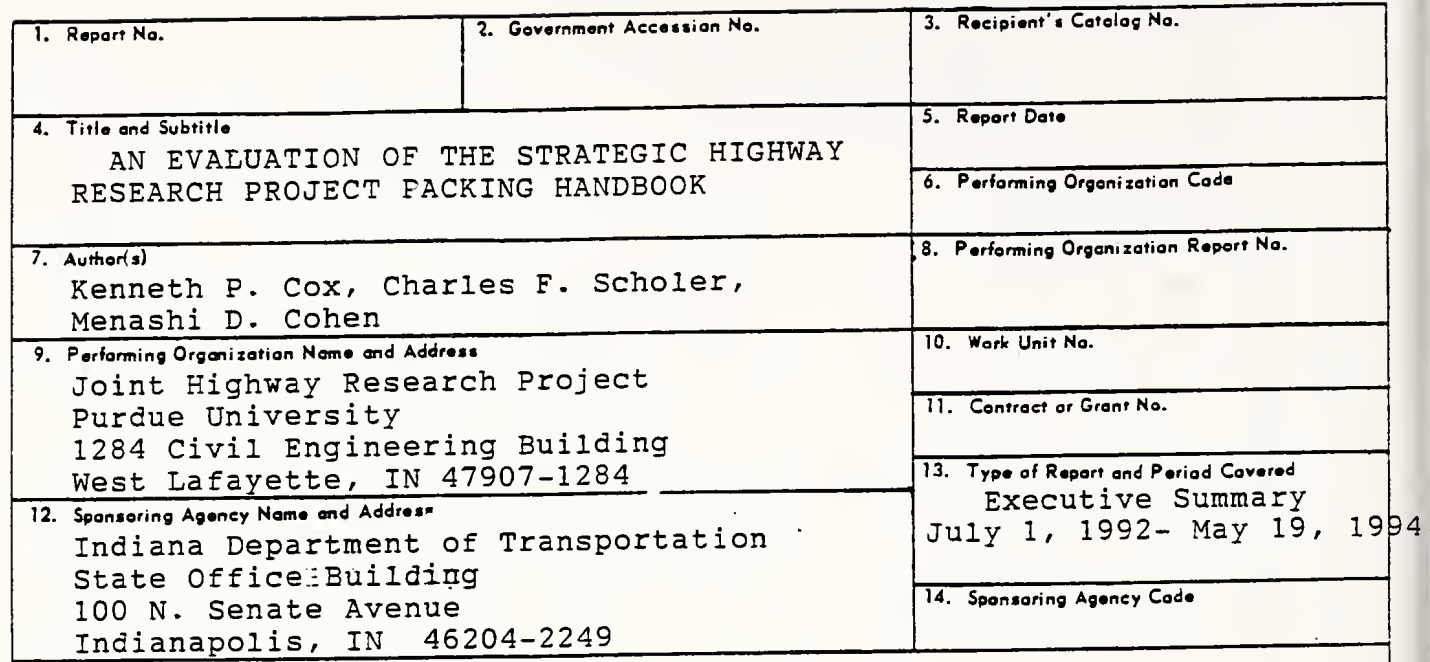

15. Supplementory Note:

16. Abstract The objective of this research is to evaluate the use of the November 8, 1991 SHRP C-206 report entitled, "Packing Handbook- A Guide to the optimal Gradation of concrete Aggregates". The purpose of the packing Handbook is to determine the optimal combination of fine and coarse aggregates for concrete from available aggregate sources. Through the use of tables provided in the Packing Handbook. and given sources with known aggregate gradations and void contents, the relative proportion of each aggregate (coarse and fine) is obtained Concretes made using the Packing Handbook recommendations of aggregate proportioning were compared to concretes used on various INDOT pavement projects. Field proportioned concretes were replicated in the laboratory. The only difference between field mixtures, the field mixtures replicated in the laboratory, and the Packing Handbook laboratory mixtures was the percent of coarse aggregate in the mixes. other proportions were held constant, $i . e$. cement content, w/c $=f a$, and the use of admixtures. The Packing Handbook was evaluated based on the comparison of engineering properties of the field control mixtures and the Packing Handbook mixtures. Packing Handbook mixes were harsh and will achieve little or no cost reductions or quality improvements if implemented for field use. Copies of this document are available on CD-ROM from the INDOT Division of Research, West Lafayette, IN.

17. Koy Words

Mix Design, Particle Packing, Aggregate, Gradation, SHRP
18. Distribution Statement

No Restriction. This document is available to the public through the National Technical Information Service, Virginia 22161
19. Security Classif. (of thi report) Unclassified
20. Security Classif. (of thi sege) Unclassified 


\section{Implementation Report}

This report summarizes the testing done at Purdue University to evaluate the "Packing Handbook - A Guide to Determine the Optimal Gradation of Concrete Aggregates." Included are the results of laboratory mixes designed with the aid of the Packing Handbook. These mixes were compared to mixes that were successfully used in recent paving projects.

Based on the results of this work, the following guidelines were developed for the implementation of the Packing Handbook.

1. The Packing Handbook can be successfully used to proportion aggregates. The Packing Handbook can be used with a variety of aggregates commonly used in the state of Indiana. The mixes with aggregate proportioned with the Packing Handbook were somewhat harsh and are best suited to applications where harsh mixes can be tolerated.

2. The Packing Handbook gives gradations higher in coarse aggregate content than current field mixes. In locations where coarse aggregate is less expensive than fine aggregate there may be an economic incentive to use the Packing Handbook.

3. Higher admixture dosages may be necessary to entrain the proper amount of air if the Packing Handbook is used to proportion aggregates. 


\section{ACKNOWLEDGMENTS}

This project is funded by the Federal Highway Administration's Office of Technology Applications (FHWA-OTA) in Washington. D. C. through and in cooperation with the Indiana Department of Transportation. The author would like to express his appreciation to his major professors, Dr. Menashi D. Cohen and Dr. Charles F. Scholer. Special thanks are also extended to Dr. Douglas Winslow for serving on the authors advisory committee and Joe Walters and Janet Lovell for their help in the laboratory.

Finally, the author would like to thank and acknowledge Mr. Pete Capon of Rieth-Riley Construction, Goshen, IN, and Mr. Richard K. Smutzer of Indiana Department of Transportation, Division of Materials and Testing for their Cooperation in providing field data and technical assistance. 
TABLE OF CONTENTS

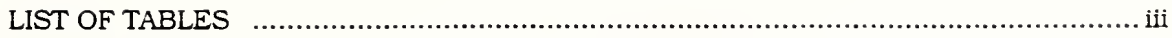

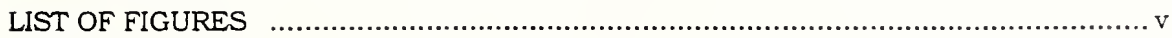

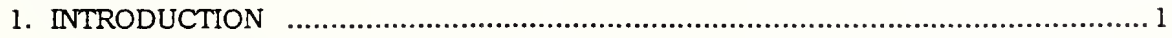

1.1 Introduction to Packing Handbook ................................................. 3

1.1.1 Packing Handbook Example Mix Design .................................5

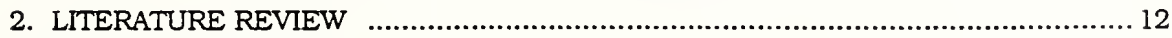

2.1 Concrete Mix Design ......................................................................... 12

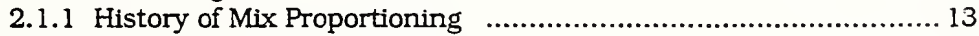

2.1.2 Current Mix Design Methods ............................................ 14

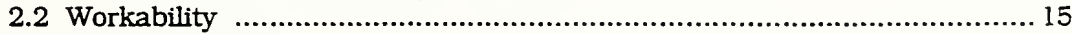

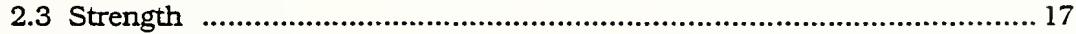

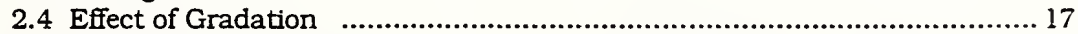

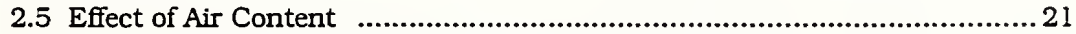

2.5.1 Influence of Air Content on Fresh Concrete ............................22

2.5.2 Influence of Air Content on Hardened Concrete .......................23

2.5.3 Factors Affecting Air Entrainment .................................... 23

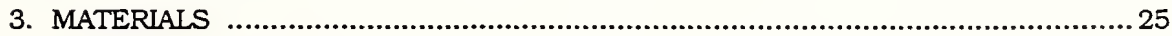

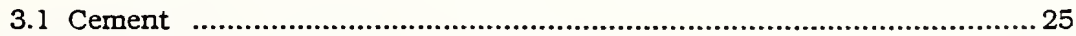

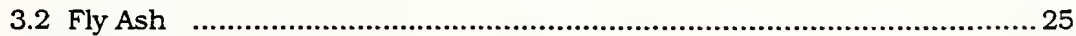

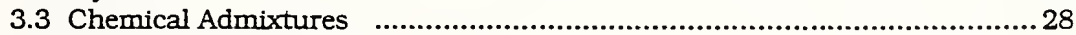

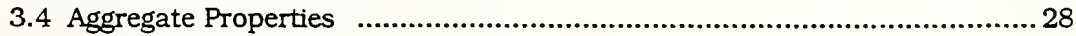

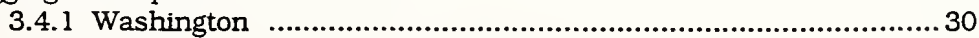

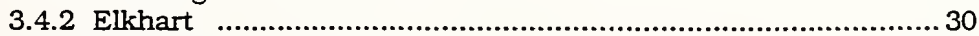

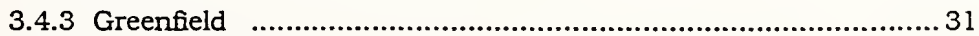

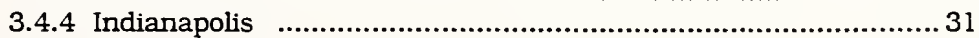

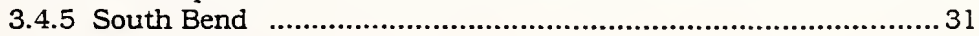

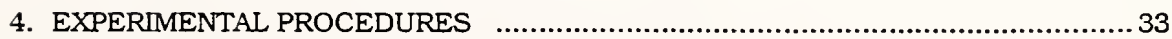

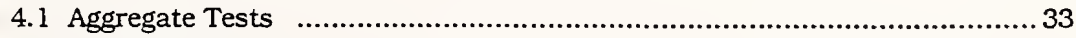

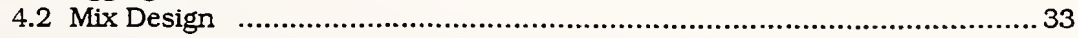

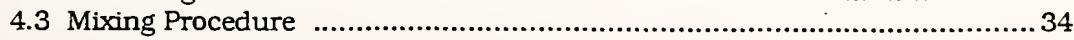




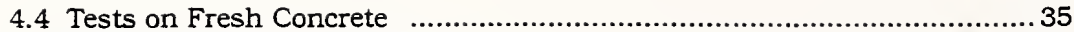

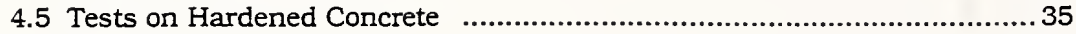

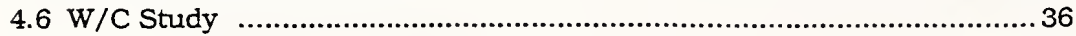

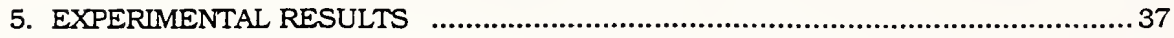

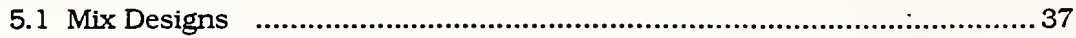

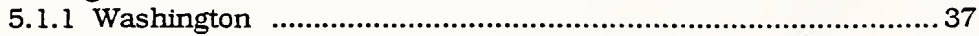

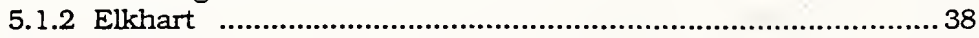

5.1.3 Greenfield ................................................................. 49

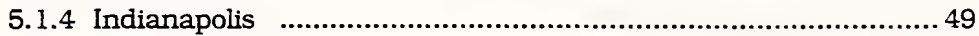

5.1.5 South Bend ..................................................................... 50

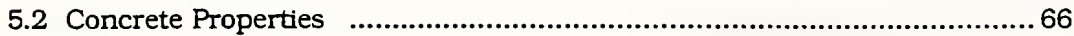

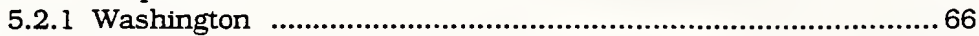

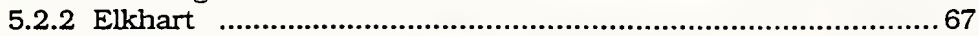

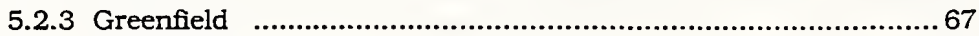

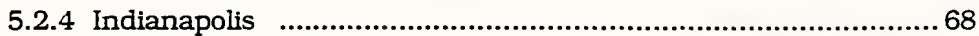

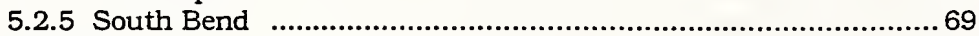

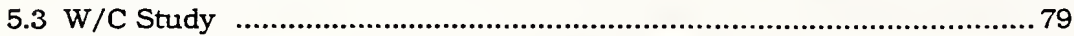

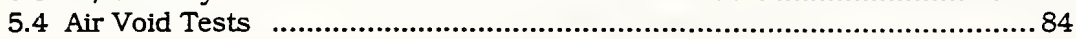

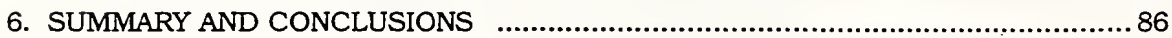

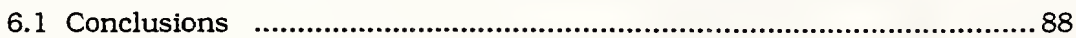

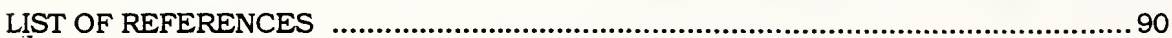


LIST OF TABLES

Table

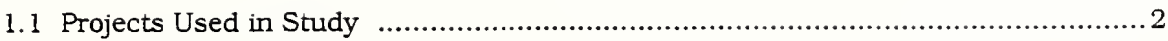

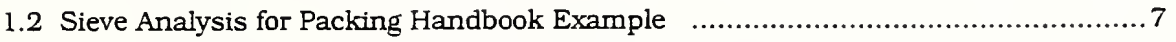

1.3 Portion of Table form Packing Handbook Giving Volume Composition .............. 10

1.4 Packing Handbook Example Mix Design ............................................ 11

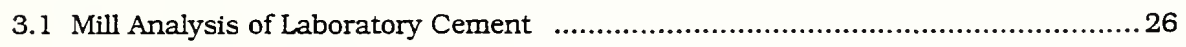

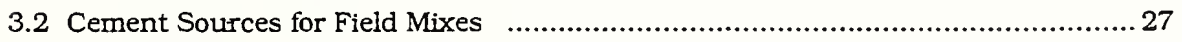

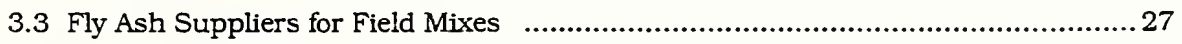

3.4 Physical and Chemical Data for Laboratory Fly Ash ...................................29

3.5 Gradation Requirements for INDOT No. 8 Coarse Aggregate ...........................32

3.6 Gradation Requirements for INDOT No. 23 Fine Aggregate ........................... 32

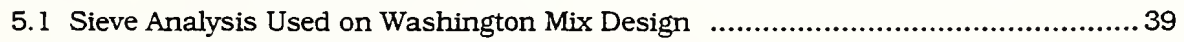

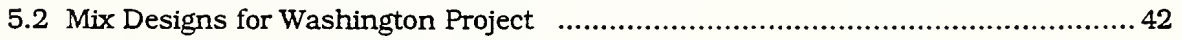

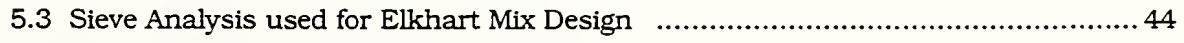

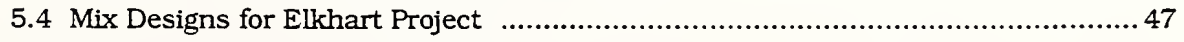

5.5 Sieve Analysis Used for Greenfield Mix Design ..................................... 51

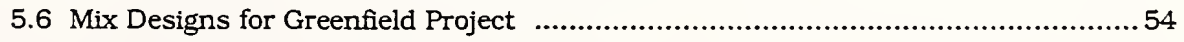

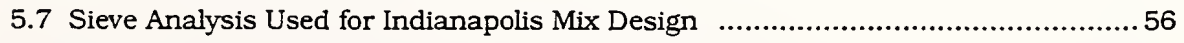

5.8 Mix Designs for Indianapolis Project .................................................. 59

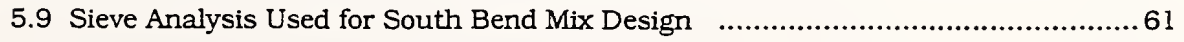

5.10 Mix Designs for South Bend Project ..................................................... 64 
Table

5.11 Concrete Properties for Trial Batches With Aggregates from Washington Project 74

5.12 Concrete Properties for Trial Batches With Aggregates from Elkhart Project ......75

5.13 Concrete Properties for Trial Batches With Aggregates from Greenfield Project .. 76

5.14 Concrete Properties for Trial Batches With Aggregates from Indianapolis Project 77

5.15 Concrete Properties for Trial Batches With Aggregates from South Bend Project 78

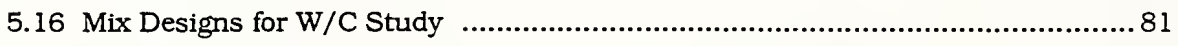

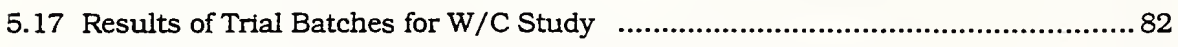

5.18 Air Void Analysis of a Packing Handbook and Field Trial Batch ....................85 


\section{LIST OF FIGURES}

Figure

1.1 Rosin-Rammler Plot of Sieve Analysis for the Fine Aggregate ......................... 8

1.2 Rosin-Rammler Plot of Sieve Analysis for the Coarse Aggregate .......................9

5.1 Plot of Coarse Aggregate Sieve Analysis for the Washington Project ................ 40

5.2 Plot of Fine Aggregate Sieve Analysis for the Washington Project ....................41

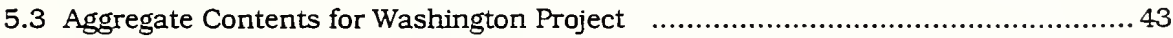

5.4 Plot of Coarse Aggregate Sieve Analysis for Elkhart Project $\ldots \ldots \ldots \ldots \ldots \ldots \ldots \ldots \ldots \ldots . \ldots \ldots$

5.5 Plot of Fine Aggregate Sieve Analysis for Elkhart Project ............................46

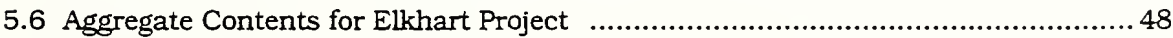

5.7 Plot of Coarse Aggregate Sieve Analysis for Greenfield Project ........................ 52

5.8 Plot of Fine Aggregate Sieve Analysis for Greenfield Project $\ldots \ldots \ldots \ldots \ldots \ldots \ldots \ldots \ldots . . . \ldots 53$

5.9 Aggregate Contents for Greenfield Project .......................................... 55

5.10 Plot of Coarse Aggregate Sieve Analysis for Indianapolis Project $\quad . \ldots \ldots \ldots \ldots \ldots \ldots . . . . .57$

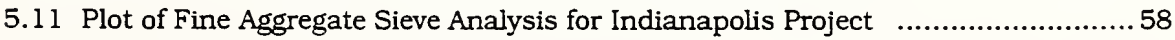

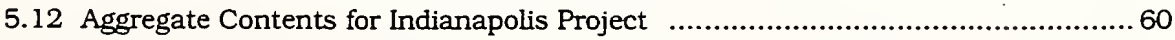

5.13 Plot of Coarse Aggregate Sieve Analysis for South Bend Project .....................6. 62

5.14 Plot of Fine Aggregate Sieve Analysis for South Bend Project .......................63

5.15 Aggregate Contents for South Bend project ......................................... 65

5.16 Slump of Packing Handbook and Field Proportioned Mixes .........................70

5.17 Air Content of Packing Handbook and Field Proportioned Mixes ....................71

5.18 Unit Weight of Packing Handbook and Field Proportioned Mixes ................... 72 
5.19 Flexural Strength of Packing Handbook and Field Proportioned Mixes .73

$5.20 \mathrm{~W} / \mathrm{C}$ vs. Strength for Water Cement Study 83 


\section{INTRODUCTION}

The purpose of this research was to evaluate the Packing Handbook developed as a product of the Strategic Highway Research Project (SHRP). This research was funded by the Federal Highway Administration's Office of Technology Applications (FHWA-OTA) in Washington, D.C. through and in cooperation with the Indiana Department of Transportation (INDOT). The evaluation of the Packing Handbook was conducted in an effort to determine what steps the Federal Highway Administration and the Indiana Department of Transportation should take in implementation of the Packing Handbook. The November 8, 1991 SHRP report "Packing Handbook - A Guide to Determine the Optimum Gradation of Concrete Aggregates" uses particle packing models to determine the maximum packing of the concrete mixture. This research and report is primarily focused on determining the benefits of using the Packing Handbook over conventional aggregate proportioning procedures currently in use.

The viability of the Packing Handbook was determined by comparing mixtures prepared using the Packing Handbook with mixtures that have been used on projects conducted for the Indiana Department of Transportation. Five projects were chosen . These projects were chosen on the basis of the type of coarse aggregate used. Three of the projects used a crushed stone as the coarse aggregate. This is by far the most common type of coarse aggregate type used on recent INDOT paving projects. A project using gravel as a coarse aggregate and one using slag were also chosen. The project using slag as a coarse aggregate was a South Bend city project and not an INDOT 
Table 1.1 Projects Used in Study

\begin{tabular}{|c|c|c|c|}
\hline $\begin{array}{c}\text { INDOT } \\
\text { Project No. }\end{array}$ & Project & $\begin{array}{c}\text { Coarse } \\
\text { Aggregate }\end{array}$ & Construction Date \\
\hline \hline R-17986 & Washington & Crushed Stone & $1991-1992$ \\
\hline R-19794 & Elkhart & Crushed Stone & 1992 \\
\hline R-19394 & Greenfield & Crushed Stone & 1992 \\
\hline R-19515 & Indianapolis & Gravel & 1992 \\
\hline South Bend & South Bend & Slag & 1992 \\
City Project & & & \\
\hline
\end{tabular}

Location of Projects

- Washington - relocation of U. S. 50 , from S. R. 57 to existing U. S. 50 east of Washington, IN

- Elkhart - U. S. 20 from Pleasant Plains Road to 0.4 of a mile northeast of County Road 18 South Bend By-pass

- Greenfield - interchange of I-465 and I-65 on the south side of Indianapolis

- Indianapolis - reconstruction of I-70 from Post Road to 0.8 of a mile east of Mohawk Road east of Indianapolis

- South Bend -extension of Mayflower and Cleveland road northwest of the South Bend airport near U. S. 20 N. 
project. Table 1.1 summarizes the project numbers, location, coarse aggregate type, and construction dates.

In this research the Packing Handbook was used to proportion the aggregates from each project. The aggregate proportions were determined for each project and then used to produce concrete mixes. The concrete mixes produced with the aid of the Packing Handbook were then compared to mixes with field proportions. Other mix preparation factors that might influence concrete properties were kept as constant as possible. This includes cement content, w/c, mixing, compaction, and finishing procedures.

\subsection{Introduction to Packing Handbook}

The Packing Handbook is meant to be used as an aid to standard mix design methods. Specifically, it is intended to serve as an extension of ACI 211.1 "Standard Practice for Selecting Proportions for Normal, Heavyweight and Mass Concrete [1]. The Packing Handbook is used to estimate the optimal combination of a sand and up to 3 different coarse aggregates [2].

The Packing Handbook outlines procedures for finding the optimum combination of aggregates. The Packing Handbook is based on principles of particle packing. The authors of the Packing handbook have studied various particle packing models and have published their findings [3]. Based on their experience they found that the position parameter of the Rosin-Rammler distribution representative of the particle size distribution, together with the experimentally determined packing density of the component can be used to predict the maximum packing density. The Rosin-Rammler distribution is described by the equation

$$
R(D)=\exp \left\{-\left(d / d^{\prime}\right)^{n}\right\}
$$


where: $d$ is the particle diameter

$R(D)$ is the cumulative probability that the diameter is less than $d$ $d^{\prime}$ is the position parameter for which $R(D)=0.368$

Their results indicated that the best workability of a concrete mixture is obtained with the densest packing of sand and coarse aggregate. From the results of tests by Johansen and Andersen, "it was found that the minimum porosity, the minimum permeability, the maximum slump, and the maximum compressive strength were achieved for mixtures with the maximum packing density" [3]. Therefore the combination of aggregates that gives the maximum density should theoretically be the best for concrete.

The method described in the Packing Handbook uses two input parameters for each aggregate. The first parameter is the characteristic diameter. This characteristic diameter is defined as the diameter corresponding to 63 weight percent passing on a best fit line of sieve analysis plotted on a Rosin-Rammler graph paper. The second parameter is the packing density of each aggregate. The packing density (PHI) is calculated by the following equation:

$$
\text { PHI }=1-(\% \text { Voids } / 100)
$$

where the percent voids is calculated in accordance with ASTM C29 "Standard Test Method for Unit Weight and Voids in Aggregate" [4].

Once these parameters are obtained for each aggregate the volumetric composition of the materials is found from tables in the Packing Handbook. The volumetric composition is found by matching the characteristic diameters for each aggregate with values in the table, and moving down in the table until the combination of input parameters is located. Absolute volume mix design procedures are used to select water content, cement content and air content. The volume of these constituents is then subtracted from the total volume to get the volume of aggregates required. 
Using the volumetric ratio of aggregates found in the table and their specific gravities, the weight of each material can be calculated. To illustrate the use of the Packing Handbook the following example is provided.

\subsubsection{Packing Handbook Example Mix Design}

Step 1

The first step in using the Packing Handbook is to plot the sieve analysis of each aggregate on Rosin-Rammler graph paper. The results of sieve analyses for both a natural siliceous sand and a crushed limestone are shown in Table 1.2. A RosinRammler plot of these sieve analyses is shown in Figure 1.1 and Figure 1.2.

\section{Step_2}

Once the sieve analysis is plotted a best fit line is drawn visually through the points. The characteristic diameters corresponding to 63 weight percent passing can then be determined. From Figures 1 and 2 the characteristic diameters of 0.054 inches for the sand and 0.59 inches (two decimal points because of log scale limitation) for the stone were found.

\section{Step 3}

After the characteristic diameters are determined the void content of each aggregate should be found according to ASTM C29. The results of ASTM C29 tests gave void contents of 34 percent for the sand, and 42 percent for the stone.

\section{Step 4}

The dry weight packing density (PHI) is then found from the void content. The calculation of packing densities gives the following: for the sand $\mathrm{PHI}=1-(34 / 100)=$ 0.66, and for the crushed limestone $\mathrm{PHI}=1-(42 / 100)=0.58$. 
Step 5

The four input values (characteristic diameters of 0.054 and 0.59 and packing densities of 0.58 and 0.66 ) are then used with the tables in the Packing Handbook to determine the volume percent of coarse aggregate. A portion of this table showing the input parameters is shown in Table 1.3. In this example the crushed limestone content recommended by the Packing Handbook is $72 \%$ of the total aggregate.

\section{Step 6}

The standard mix design procedures, of ACI 211.1, are then used to determine the cement and water contents. Once these quantities are determined the remaining volume of the concrete is occupied by the aggregate in the relative proportions recommended by the Packing Handbook. In this example the cement content and water-to-cementious materials ratio were held constant with values used in field mixtures. This gave the mix design shown in Table 1.4: 
Table 1.2 Sieve Analysis for Packing Handbook Example

\begin{tabular}{|c|c|c|}
\hline \multirow{2}{*}{ Sieve } & \multicolumn{2}{|c|}{ Percent Passing } \\
\cline { 2 - 3 } Size & Stone & Sand \\
\hline \hline $1 "$ & 100.0 & \\
\hline $3 / 4^{\prime \prime}$ & 91.7 & \\
\hline $1 / 2^{\prime \prime}$ & 41.8 & \\
\hline $3 / 8^{\prime \prime}$ & 20.6 & 100.0 \\
\hline$\# 4$ & 3.4 & 99.4 \\
\hline$\# 8$ & 1.0 & 91.0 \\
\hline$\# 16$ & & 77.9 \\
\hline$\# 30$ & & 58.1 \\
\hline$\# 50$ & & 18.0 \\
\hline$\# 100$ & & 1.3 \\
\hline$\# 200$ & & 0.3 \\
\hline
\end{tabular}




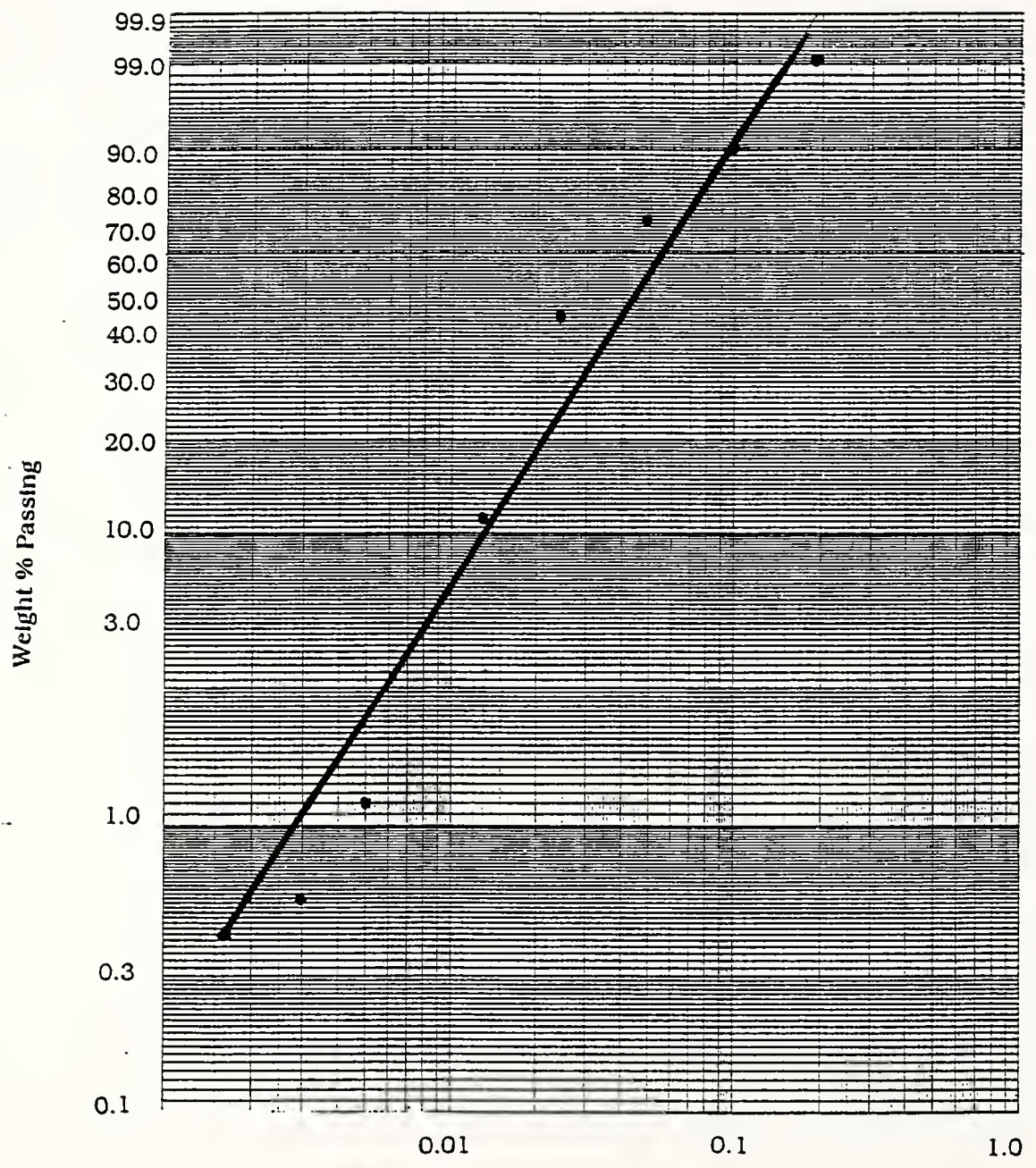

Particle size

Figure 1.1 Rosin-Rammler Plot of Sieve Analysis for the Fine Aggregate 


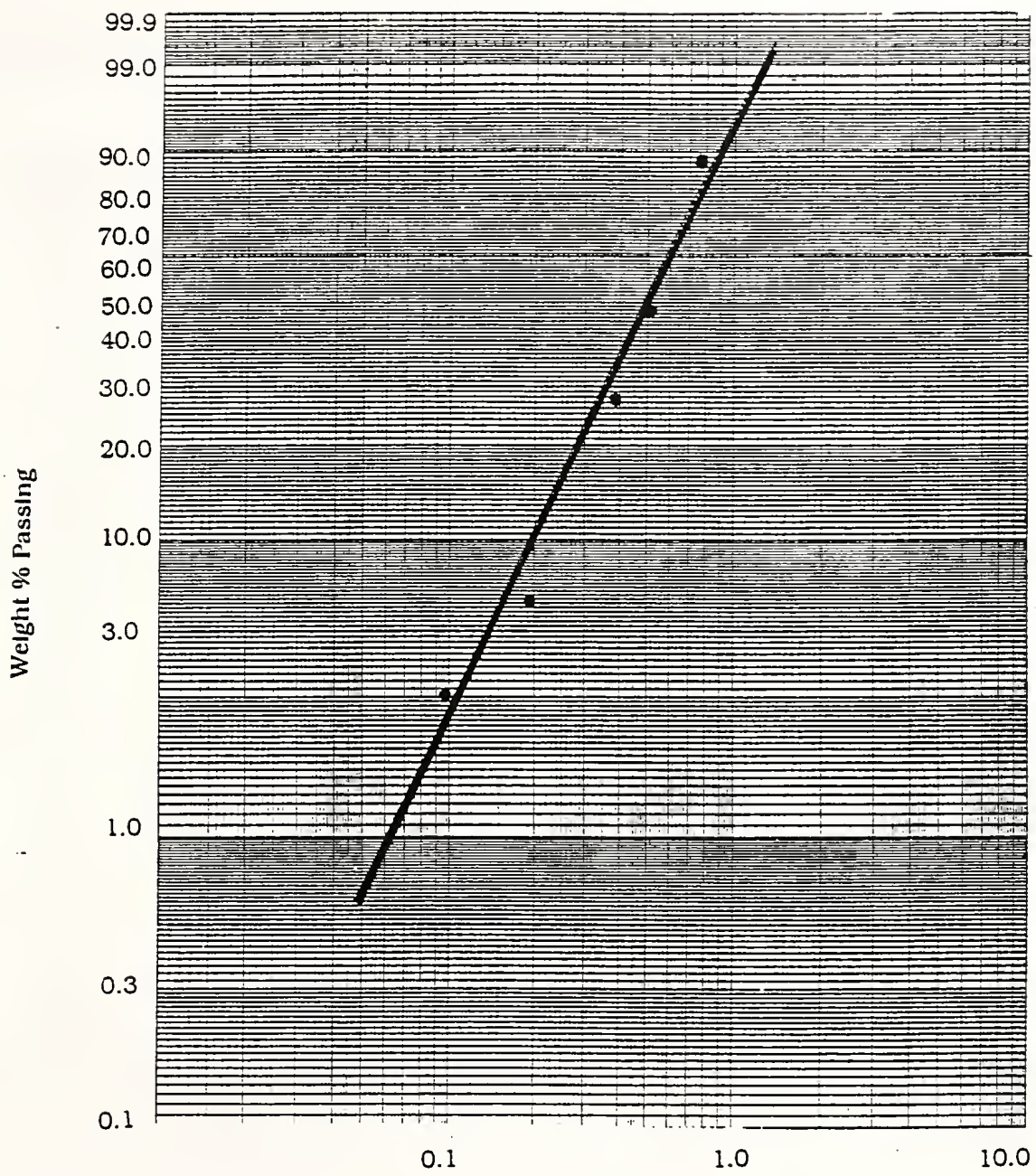

Particle size

Figure 1.2 Rosin-Rammler Plot of Sieve Analysis for the Coarse Aggregate 
Table 1.3 Portion of Table from Packing Handbook Giving Volume Composition

\begin{tabular}{|c|c|c|c|c|}
\hline DI & $\begin{array}{l}\text { PDI } \\
\text { PHI }\end{array}$ & $\begin{array}{l}\text { COARSE } \\
\text { D2 }\end{array}$ & $\begin{array}{l}\text { AGGREGATE } \\
\text { PHI, } 2\end{array}$ & $\begin{array}{c}\text { VOIUME\& } \\
\text { COARSE AGGREGATE }\end{array}$ \\
\hline $\begin{array}{l}0.06 \\
0.06 \\
0.06 \\
0.06 \\
0.06\end{array}$ & $\begin{array}{l}0.50 \\
0.55 \\
0.60 \\
0.55 \\
0.70\end{array}$ & $\begin{array}{l}0.51 \\
0.51 \\
0.51 \\
0.51 \\
0.51\end{array}$ & $\begin{array}{l}0.65 \\
0.65 \\
0.65 \\
0.65 \\
0.65\end{array}$ & $\begin{array}{l}82 \\
80 \\
78 \\
78 \\
76\end{array}$ \\
\hline $\begin{array}{l}0.06 \\
0.06 \\
0.06 \\
0.06 \\
0.06\end{array}$ & $\begin{array}{l}0.50 \\
0.55 \\
0.60 \\
0.65 \\
0.70\end{array}$ & $\begin{array}{l}0.51 \\
0.51 \\
0.51 \\
0.51 \\
0.51\end{array}$ & $\begin{array}{l}0.70 \\
0.70 \\
0.70 \\
0.70 \\
0.70\end{array}$ & $\begin{array}{l}86 \\
84 \\
84 \\
82 \\
80\end{array}$ \\
\hline $\begin{array}{l}0.06 \\
0.06 \\
0.06 \\
0.06 \\
0.06\end{array}$ & $\begin{array}{l}0.50 \\
0.55 \\
0.60 \\
0.65 \\
0.70\end{array}$ & $\begin{array}{l}0.51 \\
0.51 \\
0.51 \\
0.51 \\
0.51\end{array}$ & $\begin{array}{l}0.75 \\
0.75 \\
0.75 \\
0.75 \\
0.75\end{array}$ & $\begin{array}{l}90 \\
88 \\
88 \\
86 \\
86\end{array}$ \\
\hline $\begin{array}{l}0.06 \\
0.06 \\
0.06 \\
0.06 \\
0.06\end{array}$ & $\begin{array}{l}0.50 \\
0.55 \\
0.60 \\
0.65 \\
0.70\end{array}$ & $\begin{array}{l}0.59 \\
0.59 \\
0.59 \\
0.59 \\
0.59\end{array}$ & $\begin{array}{l}0.55 \\
0.55 \\
0.55 \\
0.55 \\
0.55\end{array}$ & $\begin{array}{l}74 \\
72 \\
70 \\
68 \\
66\end{array}$ \\
\hline $\begin{array}{l}0.06 \\
0.06 \\
0.06 \\
0.06 \\
0.06\end{array}$ & $\begin{array}{l}0.50 \\
0.55 \\
0.60 \\
0.65 \\
0.70\end{array}$ & $\begin{array}{l}0.59 \\
0.59 \\
0.59 \\
0.59 \\
0.59\end{array}$ & $\begin{array}{l}0.60 \\
0.60 \\
0.60 \\
0.60 \\
0.60\end{array}$ & $\begin{array}{l}78 \\
76 \\
74 \\
72 \\
70\end{array}$ \\
\hline
\end{tabular}


Table 1.4 Packing Handbook Example Mix Design

\begin{tabular}{rll} 
Cement $=$ & $451 \quad\left(\mathrm{lbs} / \mathrm{yd}^{3}\right)$ \\
Fly Ash $=$ & $141 \quad\left(\mathrm{lbs} / \mathrm{yd}^{3}\right)$ \\
Water $=$ & $237\left(\mathrm{lbs} / \mathrm{yd}^{3}\right)$ \\
Sand $=$ & $855\left(\mathrm{lbs} / \mathrm{yd}^{3}\right)$ \\
Stone $=$ & $2193\left(\mathrm{lbs} / \mathrm{yd}^{3}\right)$ \\
$\mathrm{AEA}$ & $=$ & $15\left(\mathrm{oz} / \mathrm{yd}^{3}\right)$ \\
\hline Total & $=$ & $3877\left(\mathrm{lbs} / \mathrm{yd}^{3}\right)$
\end{tabular}




\section{LITERATURE REVIEW}

This chapter will present the literature reviewed in an effort to analyze and evaluate the results of testing. The Packing Handbook is compared to other mix design methods. The effect of varying aggregate gradations was reviewed. Also reviewed was the effect of air content on both the plastic and hardened concrete.

\subsection{Concrete Mix Design}

The objective of all mix design methods is to produce the desired quality concrete at the minimum cost. In the usual case minimum requirements are set for strength . durability, and workability. The mix design method then attempts to combine cement, water, fine aggregate, coarse aggregate, and possibly mineral and/or chemical admixtures in the proportions that will meet the requirements with the least cost. Inadequate mix designs will result in either inefficient use of materials, or unsatisfactory performance of the fresh or hardened concrete.

Since cement is the most expensive material in concrete, costing roughly ten times as much as aggregate, the amount of cement should be kept as low as possible for a cost effective mix design. The proportions of fine and coarse aggregate are adjusted provide to adequate workability with the least amount of water. The most important factor affecting the strength of concrete is the w/c. With other variables constant the lower the $w / c$ the greater the strength of concrete. For this reason the water content should be kept as low as feasible. 


\subsubsection{History of Mix Proportioning}

A number of procedures have been developed to proportion the components of concrete mixes. Early methods were based on arbitrary assignment of quantities. The ratio of cement, fine, and coarse aggregates were set without regard to the properties of the individual components.

One of the first major attempts to apply science to the proportioning of concrete was done by Fuller and Thompson [5]. They found that for the same percentage of cement the densest mixture will be the strongest. A number of "laws" of proportioning were proposed. One of theses laws is aggregate of the largest possible size gives the densest and strongest concrete. Sand quantities should be kept at a minimum.

According the Fuller and Thompson. "The average improvement in strength by artificial grading under the conditions of the test was about $14 \% "$ [5].

Other early mix design methods also were based on the principle of least voids. Talbot proposed a mix design method based on finding the mortar with the least voids [6]. The coarse aggregate was then combined with the mortar. The amount of coarse aggregate added depended on workability requirements.

Young and Edwards both presented mix designs based on the surface area of aggregates [7,8]. The aggregate combination having the least surface area will require the least water in excess of that required for the paste. A minimum amount of surface area to be coated by paste also meant that paste content could be kept at a minimum.

In 1918 Duff Abrams asserted that the most important component in concrete was the water content [9]. Water is the most important ingredient because small variations in the water content will produce large variations in strength and durability. It is the water content that determines strength as long as the mix is of workable plasticity. The strength of concrete is a function of the w/c. The workability requirements will dictate the quantity of water. The quantity of water for a given 
workability is influenced by the quantity and quality of cement and the size, grading. adsorption and moisture of the aggregates.

Abrams stated that maximum strength of concrete does not depend on the either an aggregate of maximum density or a concrete of maximum density. The aggregate grading that gives the maximum density is not the grading that gives the greatest strength. The size and grading do not affect the strength of concrete except as these factors influence the quantity of water necessary to produce a workable mix. Abrams proposed a fineness modulus as a method to proportion the aggregates.

ACI mix design is the most common mix design procedure in the United States today. ACI attempted to formulate a standard method for mix design. The first successful attempt to produce an ACI standard was completed by Committee 613 in 1944 [10]. In 1954 the report was revised to include air entrainment and the $\mathrm{b} / \mathrm{b}_{\mathrm{o}}$ concept for estimating coarse aggregate content. The $b / b_{\circ}$ ratio is the amount of coarse aggregate in a unit volume of concrete to the amount of the same coarse aggregate compacted by rodding into a mold of the same unit volume. The basic concepts of $\mathrm{ACI}$ 613-54 are still the basis of the $\mathrm{ACI}$ procedure today.

\subsubsection{Current Mix Design Methods}

As previously mentioned $\mathrm{ACI} 211.1$ is the most common mix design procedure today. ACI 211.1 outlines a number of steps to arrive at the proportions for a concrete mix design [1]. The first step in proportioning concrete in $\mathrm{ACl} 211.1$ is to determine the raw material properties. The necessary properties are sieve analysis of both fine and coarse aggregates, unit weight of the coarse aggregate, bulk specific gravities, and absorption capacities of the aggregates. The next step requires selection of the desired slump for the concrete. Using the desired slump and the maximum aggregate size the estimate of mixing water is read from a table. The w/c necessary to fulfill strength and 
durability requirements is determined. The cement content is then calculated. The coarse aggregate content is estimated based on the fineness modulus of the sand and the dry rodded unit weight of the coarse aggregate. The fine aggregate content is then proportioned to fill the remaining volume. Finally the water content is adjusted to account for moisture in the aggregates.

British design methods take a slightly different approach [11]. The British design methods begin with the determination of a mean target strength. From this target strength the $\mathrm{w} / \mathrm{c}$ is determined. The free water is then estimated from a table and the water and cement content calculated. The total aggregate content is the calculated by subtracting the water and cement contents from the estimated wet density. The fine aggregate is then proportioned based on graphs of percent of fine aggregate vs. w/c for different maximum sizes, workabilities, and grading zones of the fine aggregate. The coarse aggregate content is then calculated by subtracting the fine aggregate from the total aggregate.

\subsection{Workability}

Workability is the collective term used to describe the properties of concrete in the plastic, or fresh state. Workability describes compactability, mobility, stability, and finishability of the concrete [12]. All of these properties must be satisfactory for quality concrete. Compactibiltiy is the ease with which the concrete is consolidated and the entrapped air removed. Mobility is the ability of the concrete to flow around reinforcement and into the comers of formwork. Stability is the resistance of the concrete to segregate. Concrete should remain as uniform as possible. Concrete must have adequate finishability for a uniform durable surface to be produced.

Workability is a difficult property to quantify. Nearly 60 methods using slump. flow, penetration, drop, mixer, deformation, compaction, and other techniques have 
been developed to measure workability [13]. These methods have succeeded only in correlating some aspect of workability or consistency with an easily determined physical measurement. The vast majority of these methods have found only limited application. The ones commonly used today are the slump, consistometer, and compaction methods. The slump method is the one most commonly used in the United States. The slump test is not used to measure workability but assure uniformity between mixes. Results of the slump test will indicate changes in water content, or grading of a mix with given materials and proportions. In the evaluation of the Packing Handbook slump was measured and the workability was observed. The workability of each mix was visually appraised.

The workability of concrete depends upon; 1) the time since mixing. 2) the properties of the aggregate, 3) the properties of the cement, 4) the relative proportions of constituents, and 5) the use of admixtures [11]. The influence of the relative mix proportions and of the aggregates are of most interest in the assessment of the Packing Handbook. Increasing the cement content increases the workability, but due to economic as well as other considerations increasing the cement content is undesirable. The workability increases as the water content rises until the point where segregation and bleeding occur. The properties of the aggregate that affect workability are particle shape, particle size distribution, porosity and surface texture. The more spherical the particles the more workable the concrete. Particle shape of both the fine and coarse aggregate affect workability, but the shape of the fine aggregate has more influence than that of the coarse aggregate [13,14]. Spherical particles act as ball bearings and have the smallest surface area per volume. The water demand for this particle shape is lower. The particle size distribution is often referred to as the gradation. The gradation is primarily controlled through the relative proportions of fine and coarse aggregate. The maximum workability is obtained at a specific ratio of coarse and fine aggregate 
$[11,14,15,16]$. The gradation and the relative proportions of aggregates will be discussed in more detail later.

\subsection{Strength}

Concrete must meet minimum strength requirements in most applications. The primary factor controlling the strength of concrete with a given cement content is the water content. For a given cement content the lower the water content, and therefore the w/c, the higher the strength. Economical mix designs use the lowest possible cement contents

Provided that aggregates are not structurally deficient and are clean they have little impact on the strength of concrete. The basis for approval of aggregate sources is to ensure that the aggregates are clean, and have adequate strength and durability. The relative proportion of fine and coarse aggregate influence the strength only in the amount of water demanded for a given workability. It is therefore desirable to have the gradation of aggregates with the least water demand [17]. A few authors maintain that the aggregate gradation giving the greatest density will also give the greatest strength $[3,5,18]$.

\subsection{Effect of Gradation}

Gradation is the size distribution of particles. The gradation is usually found with a set of standard sieves. Aggregates for use in concrete must meet certain gradation requirements $[19,20]$. Gradation of concrete mixes are primarily controlled by the ratio of fine and coarse aggregate. As stated earlier the main impact of gradation is an the workability of concrete. The goal of mix designs are to find gradations that are easily obtained, economical to produce and produce concrete of the best possible quality possible with the materials given. 
The better the gradation the more total aggregate content possible. There are a number of incentives to use as much aggregate as possible. Perhaps the most important of these is to obtain minimum cost. Thermal cracking . shrinkage, and creep are also at a minimum when the cement content is as low as possible for a given strength [21].

Mix proportioning methods have long sought to find the optimum coarse aggregate to total aggregate ratio. Many authors disagree however as to what is optimum. Some authors assert that the optimum gradation is the one that gives the maximum density of aggregates $[3,5,12,22,23]$. Other state that the optimum is the gradation with the lowest surface are possible $[7,8]$. The gradation that gives the best workability is the optimum according to another author [16]. All of these are related but not necessarily equal. Gradations with low surface area should have low water demand as should gradations based on workability or maximum density. Further complicating matters is the fact that the optimum of most or all concrete properties may not be achieved simultaneously [24]. In other words their may be numerous optimal gradings. Gradings which are optimal for strength may not be optimal for another concrete property such as impermeability.

A number of problems will develop if the aggregate grading is not satisfactory. If the percentage of sand is too high than the surface area of the aggregate will be high. This will decrease workability [13,17]. The concrete will have a drier consistency due to the increased water demand [16]. If more water is added to increase the slump to the level of a well graded mix more bleeding will take place and strength will be reduced. The porosity will increase rapidly if the voids in the fine aggregate can not be filled by the cement paste [17].

When the coarse aggregate content is excessive other problems develop. The concrete becomes harsh and difficult to consolidate. If the coarse aggregate content 
exceeds an optimum value interference becomes the dominant factor affecting workability $[13,16,17]$. Particle interference occurs when the distance between the larger particles is not sufficient to allow free passage of smaller particles [13]. The lubrication effect is thus hindered reducing workability. The voids ratio will increase and the strength will be reduced. The addition of more cement and/or fine aggregate forces the larger particles apart thus increasing the lubrication effect but this addition creates a need for more water to wet the increased surface area and strength will again be reduced [13]. Honeycombing may arise if the fine aggregate particles are unable to filter into the voids between the coarse aggregate. Sufficient sand must also be available in order to properly finish the surface. The optimum condition is for as much coarse aggregate as possible to be used while avoiding interference and maintaining adequate fine aggregate for finishing and cohesion.

Numerous methods have been proposed to arrive at the gradation for a concrete mix. Fuller and Thompson suggested the gradation should meet as closely as possible an ideal grading curve [5]. The equation to this curve is:

$$
P_{n}=100 *\left(D_{n} / D_{\max }\right)
$$

where: $P_{n}=\%$ passing sieve size $n$

$$
\mathrm{D}_{\max }=\text { maximum particle size }
$$

The theoretical basis for this empirical formula was later developed by Furnas [22]. Methods of determining gradation based on surface area were also proposed $[7,8]$.

Hughes has suggested aggregate be proportioned strictly on the basis of its effect on workability $[15,16,17,21]$. The optimum content of coarse aggregate is influenced by the ratio of the mean size of the fine aggregate to the mean size of the coarse aggregate and the loose bulk density of the coarse aggregate. This optimum content is completely independent of cement and water contents and needs to be determined only once for a given coarse and fine aggregate. 
ACI mix design proportions aggregates based on the fineness modulus of the sand, the maximum size of the coarse aggregate, and the dry rodded unit weight of the concrete. Using the dry rodded unit weight and the fineness modulus the coarse aggregate content of the mix is determined. The maximum size determines the mix water estimations. After the cement, water, and coarse aggregate are determined the remaining volume is filled with fine aggregate.

The problem of particle interference has been reduced in one method of aggregate proportioning. Interference can be reduced by eliminating the intermediate sizes in a procedure called gap grading $[25,26]$. The theory behind gap grading states that it is the intermediate particle sizes which wedge the larger aggregate sizes apart and increase the mortar required to fill the voids created. By eliminating these intermediate particles the fine aggregate can move freely into the voids between coarse aggregate particles. This results in the most efficient method of void reduction. Higher total aggregate contents can be used than conventional continuous grading.

Shilstone argues that it is the intermediate sizes that are often deficient and should be increased not reduced [27]. According to Shilstone, there are 3 factors which should be used to determine the optimum combination of aggregates. These factors are the mortar factor, the coarseness factor and the workability factor. The mortar factor is the amount of mortar, sand and paste, required for a particular construction classification. The coarseness factor is the percent of plus no. 8 material retained on the $3 / 8$ sieve, and the workability factor is the percent passing the no 8 sieve.

Finally, particle packing models have been advocated for use in concrete mix proportioning. It is particle packing models which are the basis for the Packing Handbook. Particle packing methods select appropriate sizes and proportions of particulate materials to fill larger voids with smaller particles. The density of the packed particles are influenced by the particle size distribution, the wall effect, and the 
method of compaction $[3,23]$. With a given container size and method of compaction or consolidation particle packing models, based on theoretical considerations, can be used to find the best particle size distribution. These particle packing models have not worked well in the past. The reason for the lack of success for these models is the actual internal structure of concrete does not resemble at all the actual picture that is proposed by the advocates of the maximum denseness principle [24]. The structure does not consist of symmetrically arranged contacting circles of identical diameters representing the coarse aggregate, where the remaining holes are filled first with circles of identical diameters and then with subsequent smaller circles. Thus it is little wonder the none of the ideal gradings derived mathematically from this unrealistic picture of maximum denseness in the aggregates has prove optimum for the standpoint of concrete technology [24].

\subsection{Effect of Air Content}

All concrete which will be subject to a freeze-thaw environment should be air entrained. Air entrainment is defined by $\mathrm{ACI}$ as, "the occlusion of air in the form of minute bubbles during the mixing of concrete or mortar" [52]. Chemical admixtures stabilize air bubbles trapped in the concrete during the mixing process. The main benefit of air entrainment of concrete is to increase the freeze-thaw durability.

The pore distribution of hardened portland cement is normally divided into two size classes. Capillary pores are usually defined as those larger than $0.01 \mu \mathrm{m}$. Pores smaller than this are referred to as gel pores [28]. Water will not freeze in gel pores due to there small size [29]. Water will freeze in capillary pores and as it freezes it expands. The growing crystals of ice in the capillary pores act as pumps that force the water through the gel pores towards the nearest air void boundary. This creates a hydrostatic pressure in the gel pores. If the distance between air voids is to great, the 
pressure increases to the point were it dilates the gel pores and ruptures the structure of the paste.

Therefore in order to adequately protect the paste the air voids must not be far apart. A spacing factor was developed by Powers [30] as a means of determining if the bubble distribution is adequate. The spacing factor is half the distance between bubbles on the cube diagonal, or the maximum distance from a air void boundary for any point in the paste. For properly air entrained concrete the spacing factor will be at minimum between 0.004 and 0.008 . Experience has shown that for air contents of 9 to $10 \%$ in the mortar generally give adequate bubble spacing and protection from freeze thaw damage [31,32].

\subsubsection{Influence of Air Content on Fresh Concrete}

The addition of air entrainment improves not only the durability of hardened concrete but also the properties of fresh concrete. The entrainment of air in concrete has a significant effect on the workability of concrete. The air bubbles improve workability by acting as small ball bearings aiding the flow of the concrete. The air bubbles are kept spherical by surface tension. The spherical bubbles have low surface friction and good elasticity. The addition of $5 \%$ air increases the slump by 0.5 to 2.0 inches $[28,33,34]$. Lower w/c can be used without lowering the slump.

The entrainment of air in concrete also reduces the segregation and bleeding of concrete. The precise mechanism by which air entrainment reduces bleeding and segregation is not well understood. The air bubbles make the concrete more cohesive and homogeneous. They develop a structure with the solids to which they become attached [35]. The air bubbles also buoy up the solids and reduce the tendency of the solids to settle. 


\subsubsection{Influence of Air Content on Hardened Concrete}

The primary reason for entraining air in concrete is the improvement of freeze thaw durability. The reasons for this improvement were discussed earlier. The other major effect that air entrainment has on hardened portland cement concrete is to reduce the strength. The strength of concrete is related to the concentration of solid products of hydration of the cement to the space available for these products. The concentration is often referred to as the gel/space ratio. As the amount of air in concrete increases the gel/space ratio and strength decreases. The general rule of thumb is an approximate 5 percent decrease in compressive strength for every 1 percent of entrained air. The flexural strength seems to be reduced to about the same degree [35]. The strength reduction effect of air entrainment will be partially compensated for in a well designed mix by taking advantage of the increase in workability brought on by air entrainment. The water demand is lower for the same workability, so the water content can be lowered and the $\mathrm{w} / \mathrm{c}$ will decrease.

\subsubsection{Factors Affecting Air Entrainment}

A number of factors can influence the amount of air entrained in concrete. The addition of a finely divided admixture or an excessive amount of fines in the aggregate will reduce the quantity of air entrained. Some water reducing and retarding admixtures have air entraining capabilities. The use of these admixtures without reducing the dosage of air entraining agents will result in more air being entrained. If the dosage is held constant a more workable mix will entrain more air than a less workable mix $[34,35]$. Other factors that influence the amount of air entrained include; time of mixing, size of batch, revolving speed of the drum, and the condition of the mixing blades. Finally the proportioning of aggregate especially in lean mixes affects the air content. 
Probably the most important single factor in promoting or inhibiting air entrainment is the sand, or fine aggregate, because it has the greatest effect of any one variable and it is subject to variation [32]. As the amount of sand increases the amount of air entrained increases[29,32,34,35]. An increase in sand of $5 \%$ will lead to an increase in air content of 1 to $1.5 \%$ [34]. It is generally thought that the sand between $600 \mu \mathrm{m}$. (No. 30) and $150 \mu \mathrm{m}$. (No. 100) are the most efficient at entraining air bubbles. It is a change in this size group that has the greatest effect on air content.

The addition of an air entraining admixture stabilizes bubbles formed during mixing. The air bubbles are generated by two processes [35]. The first of these processes is the infolding of air by a vortex action. This process is seen in the stirring of any liquid. The second process involves the aggregate. The aggregate acts as a three dimensional screen which entraps and holds air bubbles as the particles fall and tumble on each other during mixing. The fine aggregate and in particular the aggregate between $150 \mu \mathrm{m}$ and $600 \mu \mathrm{m}$ is the portion to the aggregate that makes up this screen. 


\section{MATERIALS}

This chapter will describe the materials used in this study. The chemical compositions of the cement and fly ash used in laboratory mixes will be given. Detailed characteristics of the aggregates used in this study will be presented.

\subsection{Cement}

All the mixes prepared both in the field and laboratory used ASTM Type 1 portland cement with one exception. The cement used for field mixes on the Washington project was a Type IA cement. The cement used for all laboratory mixes was provided by Lone Star Industries, Inc. from their Greenfield, Indiana plant. The mill analysis for this cement is given in Table 3.1 [36].

Cements used on field projects came from a variety of sources. These sources are representative of cements used on paving projects throughout the state of Indiana. The sources of the cements is provided in Table $3.2[37,38,39,40,41]$. Mill analyses of these cements were not available.

\subsection{FIv Ash}

An ASTM Class C fly ash was used for many of the laboratory and field mixes. Field mix designs for the Elkhart. Indianapolis, and South Bend projects included fly ash. The suppliers of fly ash for these projects is shown in Table 3.3.

Fly ash for laboratory mixes was supplied by American Fly Ash Company, Naperville, IL. This fly ash was obtained from Unit I of the Rockport Power Station in 
Table 3.1. Mill Analysis of Laboratory Cement

\begin{tabular}{|c|c|}
\hline Chemical Composition & Percent \\
\hline \hline $\mathrm{Si} \mathrm{O}_{2}$ & 20.72 \\
\hline $\mathrm{Al}_{2} \mathrm{O}_{3}$ & 5.42 \\
\hline $\mathrm{Fe}_{2} \mathrm{O}_{3}$ & 2.08 \\
\hline $\mathrm{CaO}$ & 65.21 \\
\hline $\mathrm{MgO}$ & 1.39 \\
\hline $\mathrm{SO} \mathrm{O}_{3}$ & 2.66 \\
\hline $\mathrm{Na} 2 \mathrm{O}$ & 0.12 \\
\hline $\mathrm{K}_{2} \mathrm{O}$ & 0.52 \\
\hline T. A. as Nan $\mathrm{O}$ & 0.46 \\
\hline Ignition Loss & 1.78 \\
\hline
\end{tabular}

\begin{tabular}{|c|c|}
\hline $\begin{array}{c}\text { Potential Compound } \\
\text { Composition }\end{array}$ & Percent \\
\hline \hline $\mathrm{C}_{3} \mathrm{~S}$ & 60.95 \\
\hline $\mathrm{C}_{2} \mathrm{~S}$ & 13.51 \\
\hline $\mathrm{C}_{3} \mathrm{~A}$ & 10.85 \\
\hline $\mathrm{C}_{4} \mathrm{AF}$ & 6.32 \\
\hline
\end{tabular}


Table 3.2 Cement Sources for Field Mixes.

\begin{tabular}{|c|c|c|}
\hline Project & Manufacturer & Plant \\
\hline \hline Washington & Lehigh & Mitchell, IN \\
\hline Elkhart & Lafarge & Alpena, MI \\
\hline Greenfield & Lonestar & Greencastle, IN \\
\hline Indianapolis & Lonestar & Greencastle. IN \\
\hline South Bend & Lafarge & Alpena, MI \\
\hline
\end{tabular}

Table 3.3. Fly Ash Suppliers for Field Mixes.

\begin{tabular}{|l|l|}
\hline Project & Fly Ash Supplier \\
\hline \hline Elkhart & National Mineral Corp. \\
\hline Indianapolis & American Fly Ash Co. \\
\hline South Bend & National Mineral Corp. \\
\hline
\end{tabular}


Southern Indiana. The physical and chemical data for this fly ash is furnished in Table $3.4[42]$.

\subsection{Chemical Admixtures}

An air entraining admixture and a water reducing admixture were used in some mixes. The air entrainment admixture used for all laboratory mixes was a neutralized vinsol resin. An ASTM Type A water reducing admixture was used in laboratory mixes when a water reducing admixture was used.in the field.

\subsection{Aggregate Properties}

In conjunction with the Indiana Department of Transportation, Division of Materials and Tests, an effort was made to select concrete construction projects with different aggregate sources. The projects selected represent materials commonly used in different regions of the state. All aggregates used in laboratory mixes were obtained from stockpiles at the site of each project.

Three projects using limestone aggregate were selected. The limestones were common aggregate sources for projects in the northern, central, and southern regions of the state. The fine aggregate sources used for these projects was also used in the laboratory mixtures. A project which used gravel, from central Indiana, as the coarse aggregate was selected. Finally, a slag coarse aggregate and sand used on a paving project in northern Indiana was sampled.

All of the aggregates used in this research were approved by Indiana Department of Transportation Standard Specifications Section 903.01 for fine aggregates, and Section 903.02 for coarse aggregates [20]. The coarse aggregates met the sieve analysis 
Table 3.4 Physical and Chemical Data for Laboratory Fly Ash

$\mathrm{SiO}_{2} \quad(\%)$

$\mathrm{Al}_{2} \mathrm{O}_{3}(\%)$

$\mathrm{Fe}_{2} \mathrm{O}_{3}(\%)$

$\mathrm{SiO}_{2}+\mathrm{Al}_{2} \mathrm{O}_{3}+\mathrm{Fe}_{2} \mathrm{O}_{3} \quad(\%)$

$\mathrm{CaO}(\%)$

MgO (\%)

Loss on Ignition

Pozzolanic Activity Index with

Cement (\%)

Specific Gravity

Mean Size $(\mu \mathrm{m})$

$\%$ > $45 \mu \mathrm{m}$
35.8

19.6

6.36

61.8

26.8

3.3

0.34

116

2.61

14

21 
requirements for a number 8 coarse aggregate. All fine aggregates met the requirements for a number 23 fine aggregate. The gradation requirements for these specifications is presented in Table 3.5 and Table 3.6.

\subsubsection{Washington}

The aggregates used on the Washington project were a crushed limestone coarse aggregate and a natural sand fine aggregate [37]. The source of the coarse aggregate was Mitchell Crushed Stone in Mitchell, IN. This limestone had a specific gravity (SSD) of 2.67 an absorption of 0.90 percent. The samples obtained had a moisture content of 0.48 percent. The source of the fine aggregate was Knox County Sand and Gravel in Vincennes, IN. The sand gathered from stockpiles used on this project had a specific gravity of 2.67 and an absorption of 1.65 percent. The moisture content of this sand was 2.10 percent.

\subsubsection{Elkhart}

A limestone crushed coarse aggregate and a natural sand fine aggregate were used on the Elkhart project [38]. The limestone came from Vulcan Materials in Kankakee, IL. The fine aggregate was also supplied by Vulcan Materials but came from Middlebury, IN. The specific gravity and absorption for the coarse aggregate are 2.67 and 2.1 percent respectively. The moisture content of this stone was 1.6 percent. The fine aggregate had an absorption of 2.5 percent and specific gravity of 2.67 . The moisture content was 3.2 percent. 


\subsubsection{Greenfield}

The Greenfield project was the last of the three limestone projects. The limestone came from Martin-Marietta in Indianapolis, IN [39]. The specific gravity of this limestone is 2.63 and absorption is 1.2 percent. The moisture content on the sample brought to the laboratory was 1.1 percent. The sand used on this project was from O K Sand in Belmont. IN. Its specific gravity was 2.61 and its absorption was 1.2 percent. The moisture content was 2.5 percent.

\subsubsection{Indianapolis}

The Indianapolis project used natural sand and gravel as its coarse and fine aggregates [40]. The gravel was supplied by Martin-Marietta Noblesville, IN. The gravel had a specific gravity of 2.63 and an absorption of 1.5 percent. The aggregate used in the laboratory mixes had a moisture content of 2.6 percent. The sand was also supplied by Martin-Marietta in Noblesville. Its specific gravity was 2.62 and absorption 1.8 percent. The moisture content of the material gathered was 2.6 percent.

\subsubsection{South Bend}

The coarse aggregate for the South Bend project was slag [41]. The slag was supplied by Levy Materials in Gary. IN and had a specific gravity of 2.39. The absorption of the slag was 4.1 percent and the moisture content was 0.4 percent. The sand was also supplied by Levy and came from South Bend. The specific gravity of the sand was 2.59 and the absorption was 1.3 percent. The moisture content of the sample obtained was 2.5 percent. 
Table 3.5 Gradation Requirements for INDOT No. 8 Coarse Aggregate.

\begin{tabular}{|c|c|}
\hline Sieve Size & \% Passing \\
\hline \hline$I^{\prime \prime}$ & 100 \\
\hline $3 / 4^{\prime \prime}$ & $75-95$ \\
\hline $1 / 2^{\prime \prime}$ & $40-70$ \\
\hline $3 / 8 "$ & $20-50$ \\
\hline$\# 4$ & $0-15$ \\
\hline$\# 8$ & $0-10$ \\
\hline$\# 30$ & ---- \\
\hline \#200 & ---- \\
\hline Decant Conc. & $0-3.0$ \\
\hline
\end{tabular}

Table 3.6 Gradation Requirements for INDOT No. 23 Fine Aggregate.

\begin{tabular}{|c|c|}
\hline Sieve Size & \% Passing \\
\hline \hline $3 / 8^{\prime \prime}$ & 100 \\
\hline$\# 4$ & $95-100$ \\
\hline$\# 8$ & $80-100$ \\
\hline$\# 16$ & $50-85$ \\
\hline$\# 30$ & $25-60$ \\
\hline$\# 50$ & $5-30$ \\
\hline$\# 100$ & $0-10$ \\
\hline$\# 200$ & $0-3$ \\
\hline
\end{tabular}




\section{EXPERIMENTAL PROCEDURES}

The experimental procedures used in this study are described in this chapter. Included is the experimental procedure for mix designs as well as batching concrete mixes. The procedures and tests used to evaluate the fresh and hardened concrete are also presented.

\subsection{Aggregate Tests}

To utilize mix design procedures, described later in this chapter, a number of aggregate properties are needed. The Packing Handbook requires that the void content, specific gravity, and sieve analysis data be obtained. The void content and unit weight of both the coarse and fine aggregates was found using the procedure specified in ASTM C29 [4]. The specific gravity and absorption values were determined according to ASTM C127 for coarse aggregates [43], and ASTM C128 for fine aggregates [44]. Sieve analysis results were gathered from each project. Laboratory sieve analysis was performed on all samples according to procedures specified in ASTM C136 [45]. The results of the lab tests were checked against field gradations to ensure that a representative sample was obtained. The results of field sieve analysis were averaged and these values used for mix design procedures.

\subsection{Mix Design}

In this study mix designs used in the field were compared to mix designs created with the Packing Handbook. Mix designs obtained from field data were used to 
proportion trial batches in the laboratory. The properties of these trial batches were then compared the those of the Packing Handbook mixes.

Mixes designed with the aid of the Packing Handbook had identical cement contents, water-to-cement ratios, and admixture dosages as the designs used in the field. The only variable that changed between the Packing Handbook and field mix designs was the relative proportions of fine and coarse aggregates.

The relative proportions of aggregates was arrived at by using the procedures outlined in the Packing Handbook [2]. The characteristic diameter for each aggregate was found by plotting the sieve analysis on Rosin-Rammler graph paper. The characteristic diameter is the diameter corresponding to 63 weight percent passing . The packing density of each aggregate was also determined. The packing density (PHI) is calculated according to the following equation: $\mathrm{PHI}=1-(\%$ voids $/ 100)$, where the $\%$ voids is determined according to ASTM C29M-90 [4]. Once these two parameters were calculated for both the fine and coarse aggregates the volumetric composition was determined using tables found in the Packing Handbook. Weight - volume relationships were then used to determine the weights of aggregate for mix design.

\subsection{Mixing Procedure}

The ASTM C 192-81 procedure was used in the preparation of all laboratory concrete batches [46]. A Lancaster pan mixer of $4.0 \mathrm{cu}$. ft. nominal capacity was used for lab mixes. Approximately $2.0 \mathrm{cu}$. ft. of concrete was mixed at a time.

Coarse aggregate and about $1 / 3$ of the mix water was added prior to starting the mixer. The mixer was then started and the sand, cement, fly ash and water were added sequentially. The air entraining admixture was mixed with the sand before the sand was placed in the mixer. Water reducing admixture were dissolved in the mix water when they were used. After all the constituents were added the concrete was mixed for 
3 minutes. After a 3 minute rest period the concrete was mixed an additional 2 minutes.

\subsection{Tests on Fresh Concrete}

Immediately after mixing a slump test was conducted according to ASTM C 14378 [47]. The unit weight of the concrete was found using the procedure give in ASTM C 138-81 [48]. The air content of the concrete was determined using the standard pressure method ASTM C 231-82 [49]. An aggregate correction factor of $0.3 \%$ was used for all projects, except for the South Bend project. The aggregate correction factor for the South Bend project which used slag as its coarse aggregate was $2.4 \%$. Because of the high correction factor the Indiana Department of Transportation requires that the air content be found using the volumetric method. For the mixes produced in the laboratory the air content was determined with the pressure method and the correction factor applied. A minimum of two $6 \times 6 \times 21$ inch beams were cast from each mix. The concrete was placed in steel molds and compacted with a 1.5 inch spud vibrator. The amount of effort required to compact both the Packing Handbook mixes and the field mixes was noted. The top of the mold was struck off and the concrete was trowel finished. The difficulty in striking off and trowel finishing the top surface of the beams was also noted. After casting the beams were covered with plastic and kept in the molds for 24 hours. The beams were then demolded and stored in a fog room until the time of testing.

\subsection{Tests on Hardened Concrete}

The flexural strength of concrete was determined using $6 \times 6 \times 21$ in. beams and the procedure given in ASTM C 78-84 (third-point loading) [50]. The beams were taken from the fog room and tested after a period of 7 days. The beams were tested with the 
top surface at time of casting placed on the front or back face of the beam. The beams were tested in a Baldwin hydraulic universal testing machine at a loading rate of 1800 $\mathrm{lbs} / \mathrm{min}$. This corresponds to a increase in extreme fiber stress of $150 \mathrm{psi} / \mathrm{min}$.

Testing was also done on 2 samples to determine the characteristics of the air void system. The testing was done in accordance with the modified point count method as specified in ASTM C457-82 [51]. The purpose of this testing was to determine the adequacy of the air void system for a Packing Handbook mix with a low air content. 3.0 percent, and determine the air void system characteristics of a field mix with a high air content, 9.5 percent.

\section{$4.6 \mathrm{~W} / \mathrm{C}$ Study}

A number of mixes were prepared in an effort to determine the effect of various $w / c$ on the properties of mixes designed with the aid of the Packing Handbook. The aggregates used on the Elkhart project were selected for these mixes. Relative proportions of aggregates were calculated according to the Packing Handbook for Packing Handbook mixes. Aggregate relative proportions for field mixes were identical to the proportions used on the Elkhart project. The cement content was held constant at $600 \mathrm{lbs} / \mathrm{yd}^{3}$. The water content was then adjusted to give $\mathrm{w} / \mathrm{c}$ of $0.35,0.40,0.45$, and 0.50 .

The trial batches for the $w / c$ testing were mixed at the facilities of Rieth-Riley Construction, Goshen, IN. The mixing procedure for the $w / c$ testing was as previously specified for other laboratory mixes with the following exceptions. A tilting drum mixer was used instead of a pan mixer. Admixture dosages were not kept constant with field proportions but adjusted in an effort to maintain constant slump and air contents between Packing Handbook and field mixes. Flexural strength specimens were cast and tested following the same procedure previously specified for other laboratory mixes. 


\section{EXPERIMENTAL RESULTS}

This chapter will present the findings of experimental mix design and aggregate properties obtained to develop the mix designs. The properties of trial batches made with each mix design will also given. The differences between the Packing Handbook mix designs and the field mix designs will be shown.

\subsection{Mix Designs}

Mix designs were prepared using the Packing Handbook for each project. As discussed before the Packing Handbook mix designs were identical to the field mix designs except for the relative aggregate proportions. For each project the results of tests done to determine this relative proportion for each aggregate source is provided in this section. The field mix designs and Packing Handbook mix designs are given and aggregate proportions compared.

\subsubsection{Washington}

The first step in determining the aggregate proportions for mix design using the Packing Handbook is to obtain sieve analysis data. The sieve analysis data for the Washington project is shown in Table 5.1. This sieve analysis was then plotted on Rosin-Rammler graph paper. The sieve analysis is plotted in Figure 5.1 for the coarse aggregate and Figure 5.2 for the fine aggregate. The characteristic diameter can then be determined from this graph. The characteristic diameter is the diameter corresponding to 63 weight percent passing. The characteristic diameter for the coarse 
aggregate was 0.68 inches and the characteristic diameter of the fine aggregate was 0.054 inches.

The next property needed is the packing density. The packing density is a function of the void content ( $\%$ voids) as calculated by ASTM C29 [4]. The packing density for the coarse aggregate is 0.57 and 0.66 for the fine aggregate. Once the packing density and characteristic diameter for each aggregate is found the tables in the Packing Handbook are used to determine the volume percent of coarse aggregate. The ratio of coarse aggregate to total aggregate for this project is $0.66 \%$. Using weight volume relationships the mix design weights can then be determined. The Packing Handbook and field mix designs for the Washington project are shown in Table 5.2. A graphical comparison of the aggregate proportions is given in Figure 5.3.

\subsubsection{Elkhart}

The sieve analysis for the fine and coarse aggregate used on the Elkhart project is furnished in Table 5.3. The fine aggregate sieve analysis is plotted in Figure 5.4 and the coarse aggregate sieve analysis is plotted in Figure 5.5. The characteristic diameters from these plots is 0.59 for the coarse aggregate and 0.054 for the fine aggregate.

The packing density of the coarse aggregate used on the Elkhart project is 0.58 . The packing density of the fine aggregate is 0.66 . When these packing density and characteristic diameters are used as input values for the tables in the Packing Handbook the volume percent of coarse aggregate obtained is $72 \%$. When this volume percent of coarse aggregate is used the mix design shown in Table 5.4 is calculated. Also shown in this table is the field mix design. The relative proportions of coarse and fine aggregate are shown in Figure 5.6. This shows both the fine and.coarse aggregate content for the field and Packing Handbook mix designs. 
Table 5.1 Sieve Analysis Used for Washington Mix Design

\section{Coarse Aggregate}

\begin{tabular}{|c|c|}
\hline Sieve Size & Percent Passing \\
\hline \hline 1 in. & 100 \\
\hline $3 / 4$ in. & 90.4 \\
\hline $1 / 2$ in. & 45.4 \\
\hline $3 / 8$ in. & 25.6 \\
\hline$\# 4$ & 6.8 \\
\hline$\# 8$ & 2.7 \\
\hline
\end{tabular}

Fine Aggregate

\begin{tabular}{|c|c|}
\hline$\cdots$ Sieve Size & Percent Passing \\
\hline \hline $3 / 8$ in. & 100 \\
\hline$\# 4$ & 99.6 \\
\hline$\# 8$ & 88.2 \\
\hline$\# 16$ & 70.2 \\
\hline$\# 30$ & 44.5 \\
\hline$\# 50$ & 12.8 \\
\hline$\# 100$ & 1.45 \\
\hline$\# 200$ & 0.7 \\
\hline
\end{tabular}




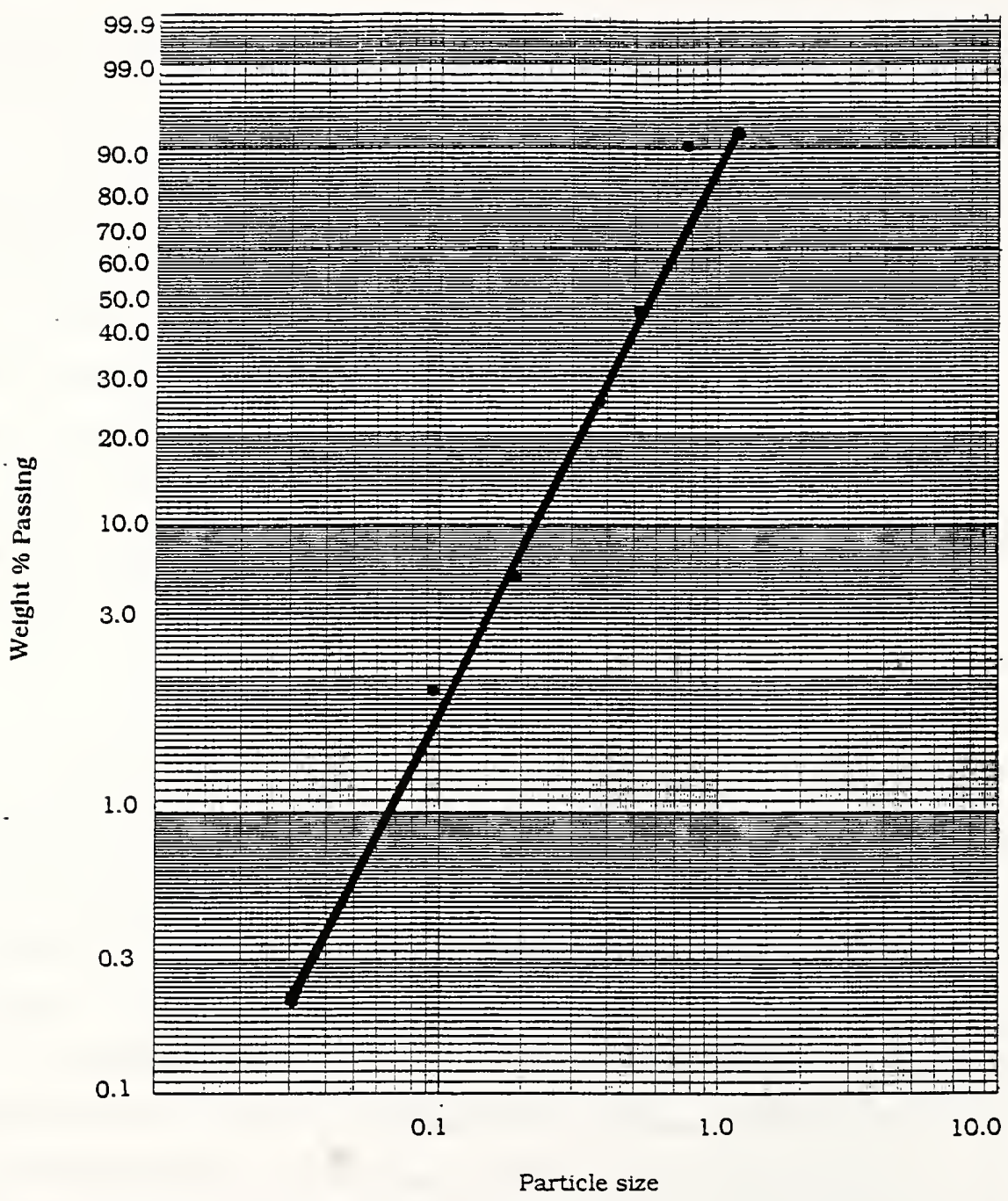

Figure 5.1 Plot of Coarse Aggregate Sieve Analysis for Washington Project 


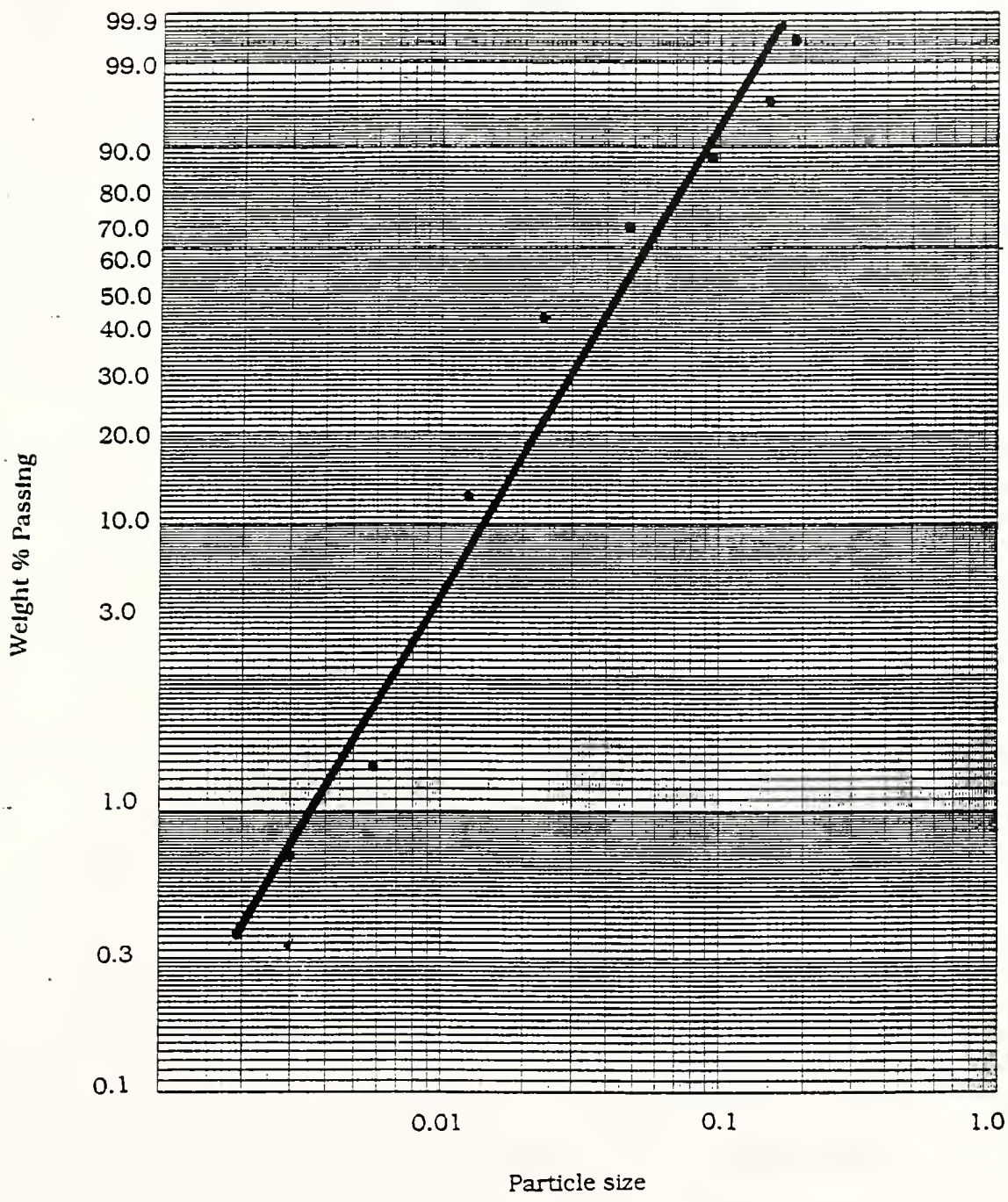

Figure 5.2 Plot of Fine Aggregate Sieve Analysis for Washington Project 
Table 5.2 Mix Designs for Washington Project

Field mix design

\begin{tabular}{|l|l|}
\hline & $\mathrm{lbs} / \mathrm{yd}^{3}$ \\
\hline Cement & 475 \\
\hline Fly Ash & \\
\hline Water & 209 \\
\hline Fine Aggregate & 1379 \\
\hline Coarse Aggregate & 1887 \\
\hline AEA (oz/yd 3 ) & 10 \\
\hline WRA (oz/yd $\left.{ }^{3}\right)$ & \\
\hline
\end{tabular}

Packing Handbook mix design

\begin{tabular}{|l|l|}
\hline & $\mathrm{lbs} / \mathrm{yd}^{3}$ \\
\hline Cement & 475 \\
\hline Fly Ash & \\
\hline Water & 209 \\
\hline Fine Aggregate & 1112 \\
\hline Coarse Aggregate & 2153 \\
\hline AEA (oz/yd 3 ) & 10 \\
\hline WRA (oz/yd 3 ) & \\
\hline
\end{tabular}


Washington Mix Design

Field vs. Packing Handbook

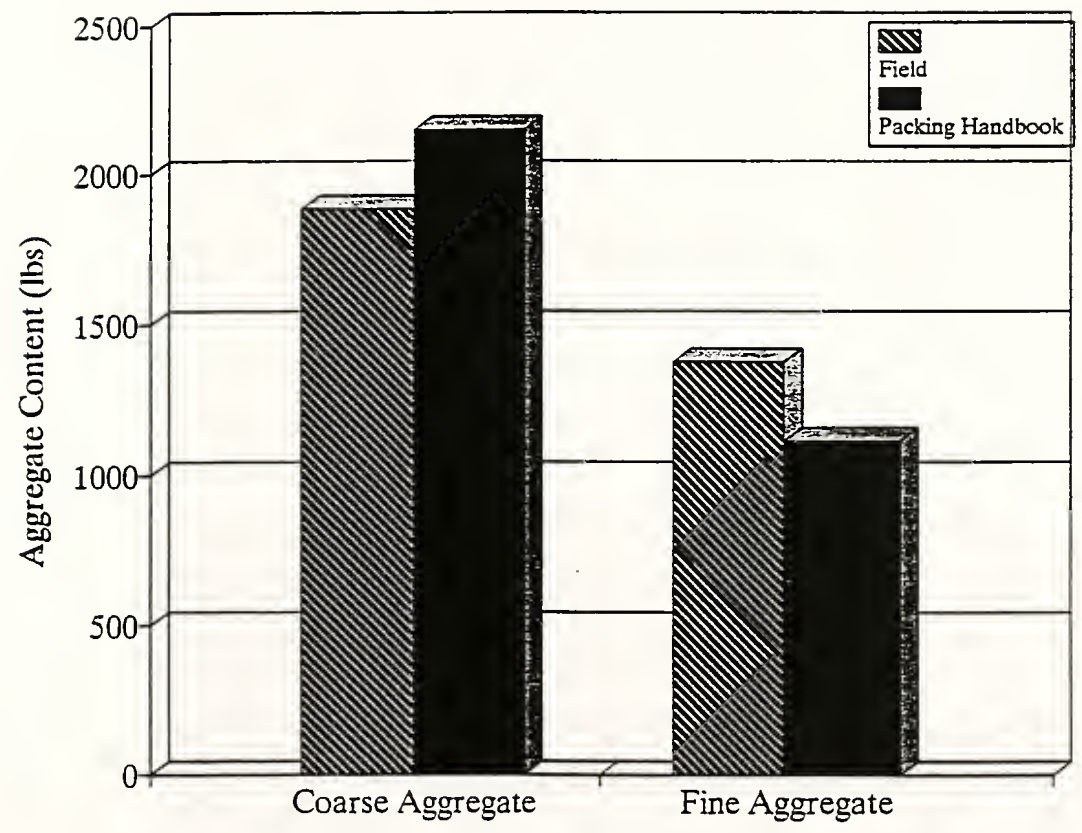

Figure 5.3 Aggregate Contents for Washington Project 
Table 5.3 Sieve Analysis Used for Elkhart Mix Design Coarse Aggregate

\begin{tabular}{|c|c|}
\hline Sieve Size & Percent Passing \\
\hline \hline 1 in. & 100 \\
\hline $3 / 4$ in. & 89.0 \\
\hline $1 / 2$ in. & 47.4 \\
\hline $3 / 8$ in. & 27.7 \\
\hline$\# 4$ & 6.4 \\
\hline$\# 8$ & 3.2 \\
\hline
\end{tabular}

Fine Aggregate

\begin{tabular}{|c|c|}
\hline Sieve Size & Percent Passing \\
\hline \hline $3 / 8$ in. & 100 \\
\hline$\# 4$ & 99.2 \\
\hline$\# 8$ & 90.3 \\
\hline$\# 16$ & 73.2 \\
\hline$\# 30$ & 45.4 \\
\hline$\# 50$ & 11.3 \\
\hline$\# 100$ & 1.2 \\
\hline$\# 200$ & 0.6 \\
\hline
\end{tabular}




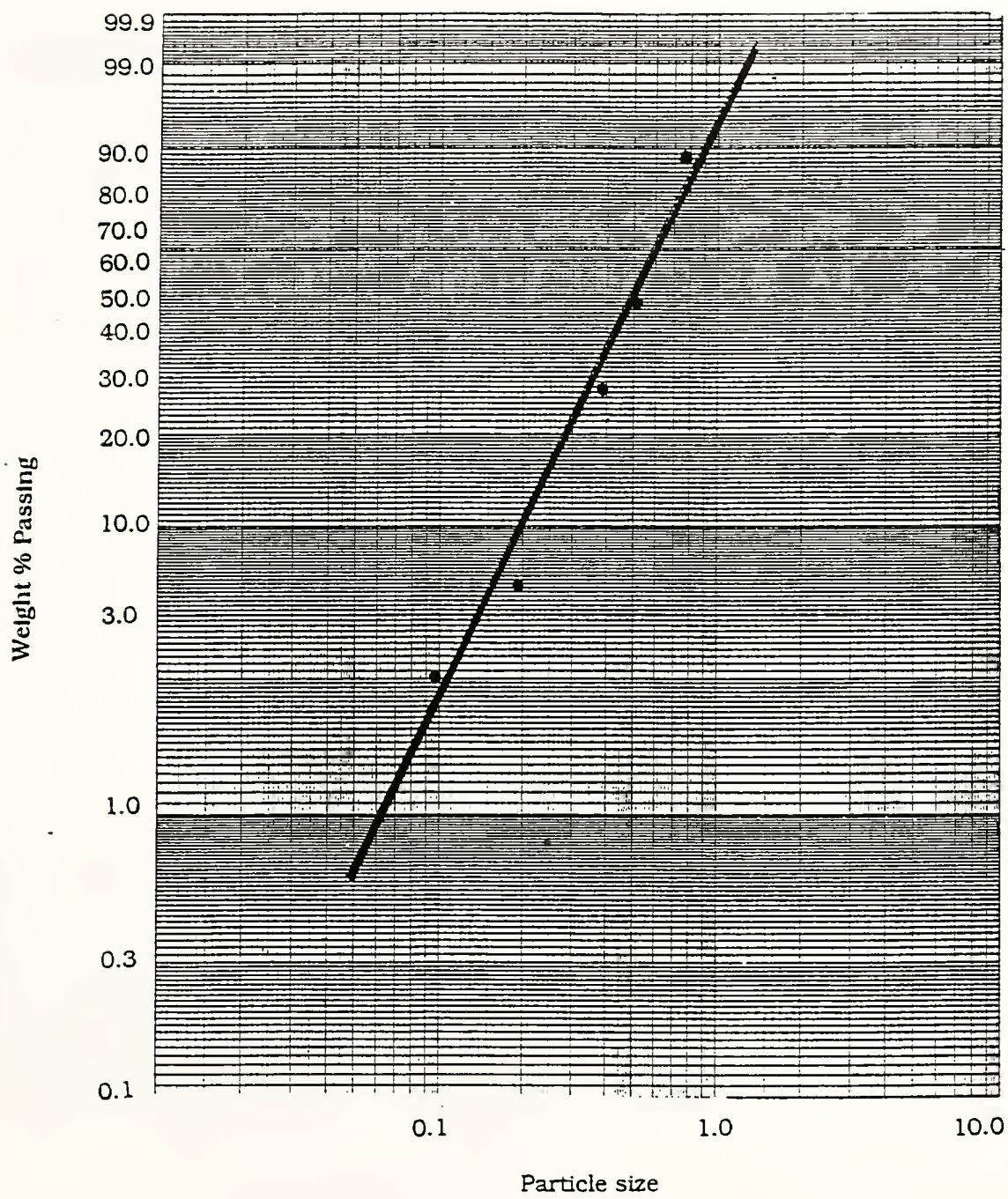

Figure 5.4 Plot of Coarse Aggregate Sieve Analysis for Elkhart Project 


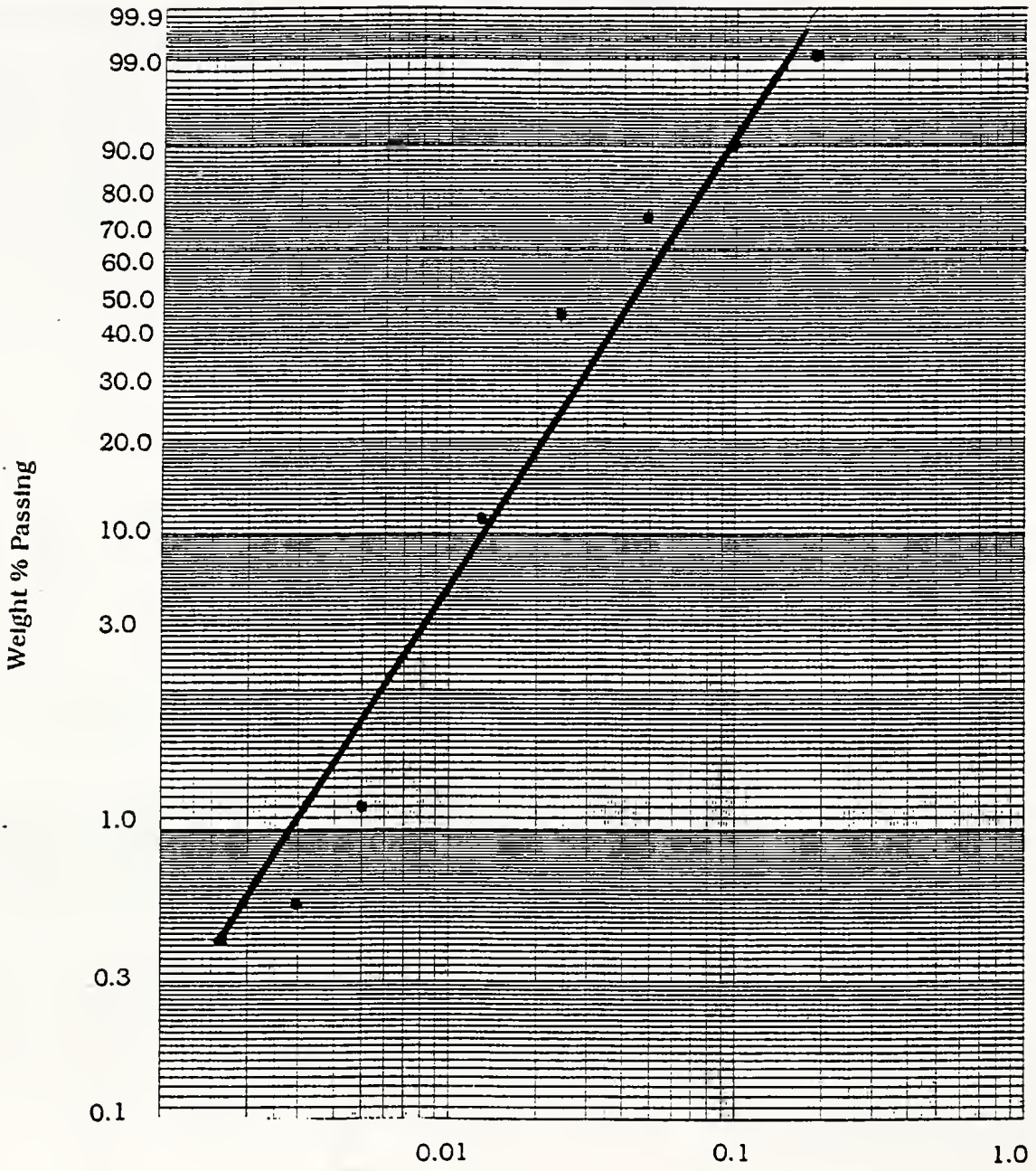

Particle size

Figure 5.5 Plot of Fine Aggregate Sieve Analysis for Elkhart Project 
Table 5.4 Mix Designs for Elkhart Project

Field mix design

\begin{tabular}{|l|l|}
\hline & $\mathrm{lbs} / \mathrm{yd}^{3}$ \\
\hline Cement & 451 \\
\hline Fly Ash & 141 \\
\hline Water & 237 \\
\hline Fine Aggregate & 1182 \\
\hline Coarse Aggregate & 1865 \\
\hline AEA (oz/yd 3 ) & 15 \\
\hline WRA (oz/yd 3 ) & \\
\hline
\end{tabular}

Packing Handbook mix design

\begin{tabular}{|l|l|}
\hline & $\mathrm{lbs} / \mathrm{yd}^{3}$ \\
\hline Cement & 451 \\
\hline Fly Ash & 141 \\
\hline Water & 237 \\
\hline Fine Aggregate & 855 \\
\hline Coarse Aggregate & 2193 \\
\hline AEA (oz/yd 3 ) & 15 \\
\hline WRA (oz/yd 3 ) & \\
\hline
\end{tabular}


Elkhart Mix Design

Field vs. Packing Handbook

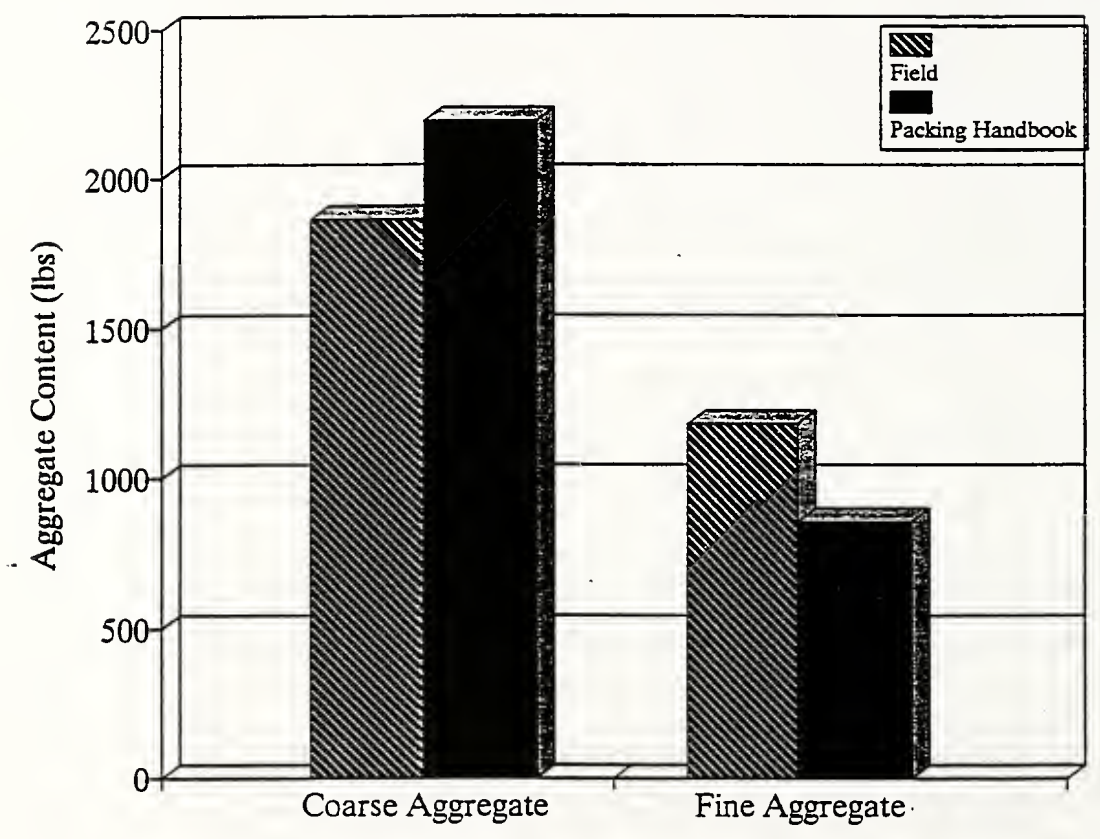

Figure 5.6 Aggregate Contents for Elkhart Project 


\subsubsection{Greenfield}

Sieve analysis of the aggregates used on the Greenfield project were obtained. The average of these sieve analyses used on the Greenfield project is provided in Table 5.5. The sieve analysis for the coarse aggregate was plotted on Rosin-Rammler graph paper in Figure 5.7. Figure 5.8 shows the fine aggregate plot of sieve analysis. From these plots the characteristic diameters of 0.58 inches for the coarse aggregate and 0.044 inches for the fine aggregate were determined.

The packing density for both aggregates used on the project was then calculated. The packing density for the coarse aggregate is 0.57 , and 0.69 for the fine aggregate. These four values for characteristic diameter and packing density yielded a coarse aggregate content of $64 \%$ from the tables in the Packing Handbook. This value was used to proportion the Packing Handbook mix. Both the field mix and the Packing Handbook mixes are shown in Table 5.6. The aggregate proportions are also shown in Figure 5.9.

\subsubsection{Indianapolis}

The sieve analyses used for determining proportions on the Indianapolis project are given in Table 5.7. Figure 5.10 and Figure 5.11 show the plots of these analyses on Rosin-Rammler graph paper for coarse and fine aggregates respectively. The characteristic diameters form these plots are 0.56 inches for the coarse aggregate and 0.06 inches for the fine aggregate.

The packing densities for each of these aggregates was also determined. The packing density of the coarse aggregate was 0.66 . The packing density of the fine aggregate was 0.65 . The volumetric composition found from the tables was $76 \%$ coarse aggregate. The Packing Handbook and field mix designs are given in Table 5.8. A graph of the aggregate contents of both mix designs is presented in Figure 5.12. 


\subsubsection{South Bend}

The final project studied was South Bend. The sieve analyses used for mix design on this project are shown in Table 5.9. The plot of these sieve analyses is presented in Figure 5.13 for the coarse aggregate and Figure 5.14 for the fine aggregate. The characteristic diameter for the coarse aggregate is 0.50 inches. The characteristic diameter for the fine aggregate is 0.04 inches.

The packing density of each aggregate was determined. The packing density of the coarse aggregate was 0.54 . The packing density of the fine aggregate was 0.67 . A volumetric composition of $66 \%$ coarse aggregate was obtained through the use of the Packing Handbook with these input variables. The resulting Packing Handbook mix design and the field mix design are a given in Table 5.10. The graphical representation of the aggregate contents is provided in Figure 5.15. 
Table 5.5 Sieve Analysis Used for Greenfield Mix Design

Coarse Aggregate

\begin{tabular}{|c|c|}
\hline Sieve Size & Percent Passing \\
\hline \hline 1 in. & 100 \\
\hline $3 / 4$ in. & 89.7 \\
\hline $1 / 2$ in. & 48.8 \\
\hline $3 / 8$ in. & 28.1 \\
\hline$\# 4$ & 5.6 \\
\hline$\# 8$ & 2.1 \\
\hline
\end{tabular}

Fine Aggregate

\begin{tabular}{|c|c|}
\hline Sieve Size & Percent Passing \\
\hline \hline $3 / 8$ in. & 100 \\
\hline$\# 4$ & 100 \\
\hline$\# 8$ & 93.2 \\
\hline$\# 16$ & 48.71 \\
\hline$\# 30$ & 18.2 \\
\hline$\# 50$ & 2.91 \\
\hline$\# 100$ & 2.9 \\
\hline$\# 200$ & 1.3 \\
\hline
\end{tabular}




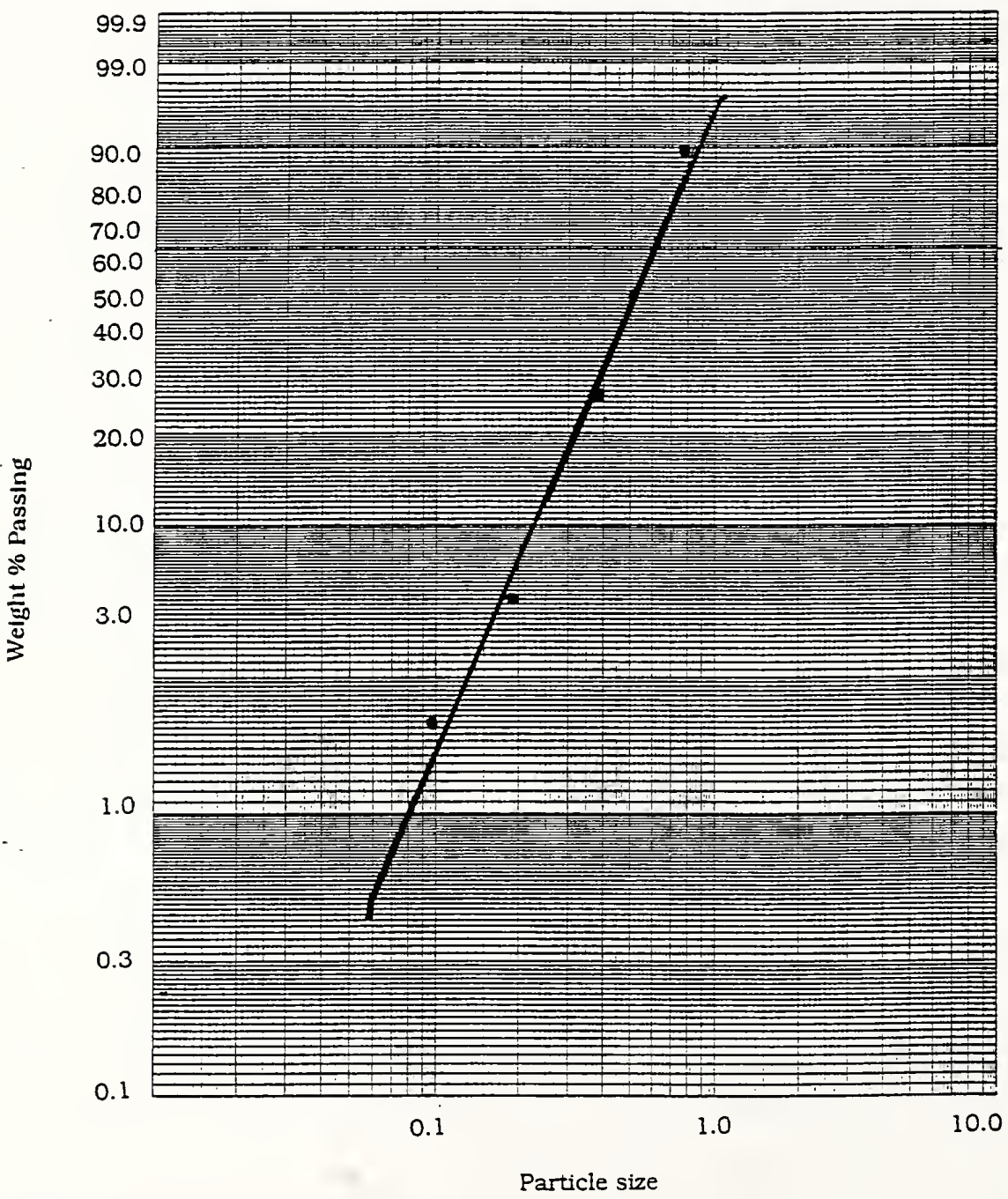

Figure 5.7 Plot of Coarse Aggregate Sieve Analysis for Greenfield Project 


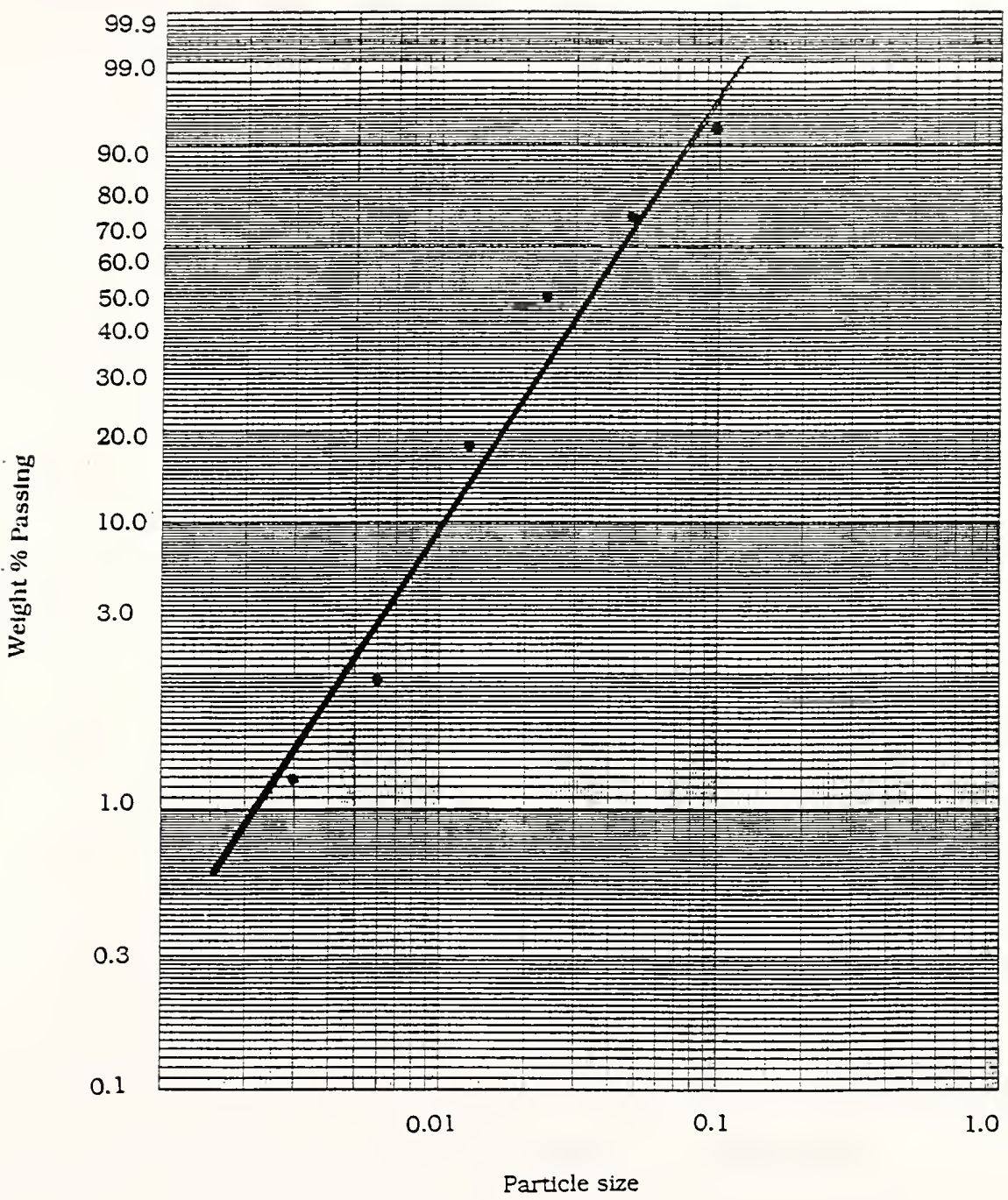

Figure 5.8 Plot of Fine Aggregate Sieve Analysis for Greenfield Project 
Table 5.6 Mix Designs for Greeenfield Project

Field mix design

\begin{tabular}{|l|l|}
\hline & $\mathrm{lbs} / \mathrm{yd}^{3}$ \\
\hline Cement & 564 \\
\hline Fly Ash & \\
\hline Water & 233 \\
\hline Fine Aggregate & 1394 \\
\hline Coarse Aggregate & 1798 \\
\hline AEA (oz/yd 3 ) & 5 \\
\hline WRA (oz $\left./ \mathrm{yd}^{3}\right)$ & 30 \\
\hline
\end{tabular}

Packing Handbook mix design

\begin{tabular}{|l|l|}
\hline & $\mathrm{lbs} / \mathrm{yd}^{3}$ \\
\hline Cement & 564 \\
\hline Fly Ash & \\
\hline Water & 233 \\
\hline Fine Aggregate & 1158 \\
\hline Coarse Aggregate & 2044 \\
\hline AEA (oz/yd $\left.{ }^{3}\right)$ & 5 \\
\hline WRA (oz/yd $\left.3{ }^{3}\right)$ & 30 \\
\hline
\end{tabular}


Greenfield Mix Design

Field vs. Packing Handbook

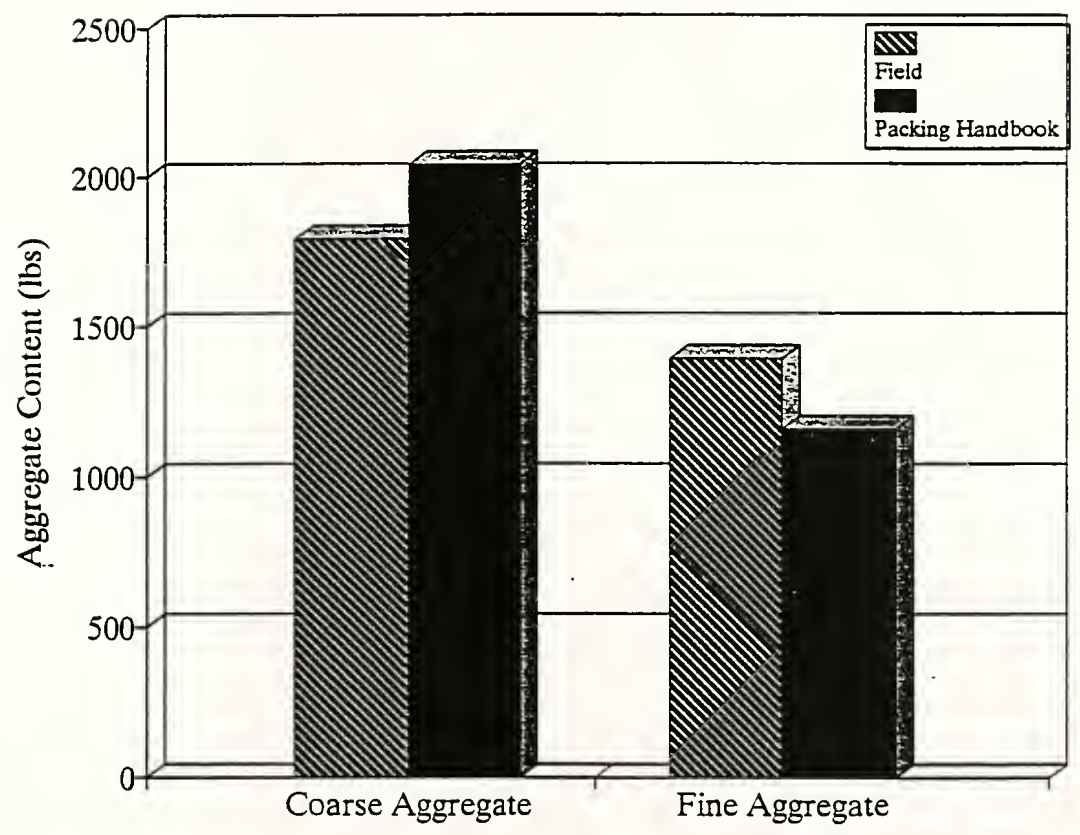

Figure 5.9 Aggregate Contents for Greenfield Project 
Table 5.7 Sieve Analysis Used for Indianapolis Mix Design

Coarse Aggregate

\begin{tabular}{|c|c|}
\hline Sieve Size & Percent Passing \\
\hline 1 in. & 100 \\
\hline $3 / 4$ in. & 91.1 \\
\hline $1 / 2$ in. & 56.7 \\
\hline $3 / 8$ in. & 33.3 \\
\hline$\# 4$ & 7.4 \\
\hline$\# 8$ & 1.3 \\
\hline
\end{tabular}

Fine Aggregate

\begin{tabular}{|c|c|}
\hline Sieve Size & Percent Passing \\
\hline \hline 3/8 in. & 100 \\
\hline$\# 4$ & 99.8 \\
\hline$\# 8$ & 94.2 \\
\hline$\# 16$ & 72.4 \\
\hline$\# 30$ & 44.6 \\
\hline$\# 50$ & 10.3 \\
\hline$\# 100$ & 1.9 \\
\hline & 0.8 \\
\hline
\end{tabular}




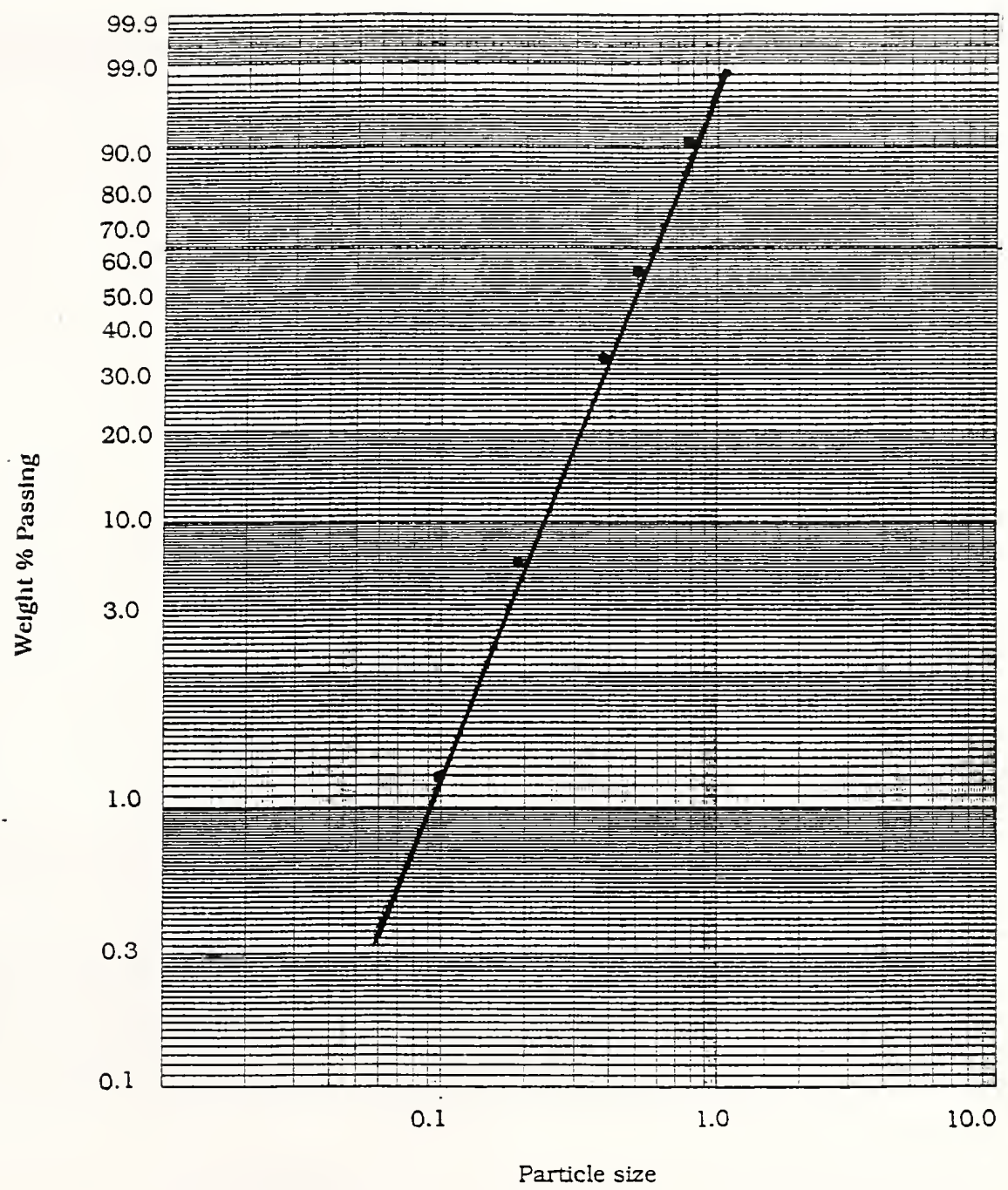

Figure 5.10 Plot of Coarse Aggregate Sieve Analysis for Indianapolis Project 


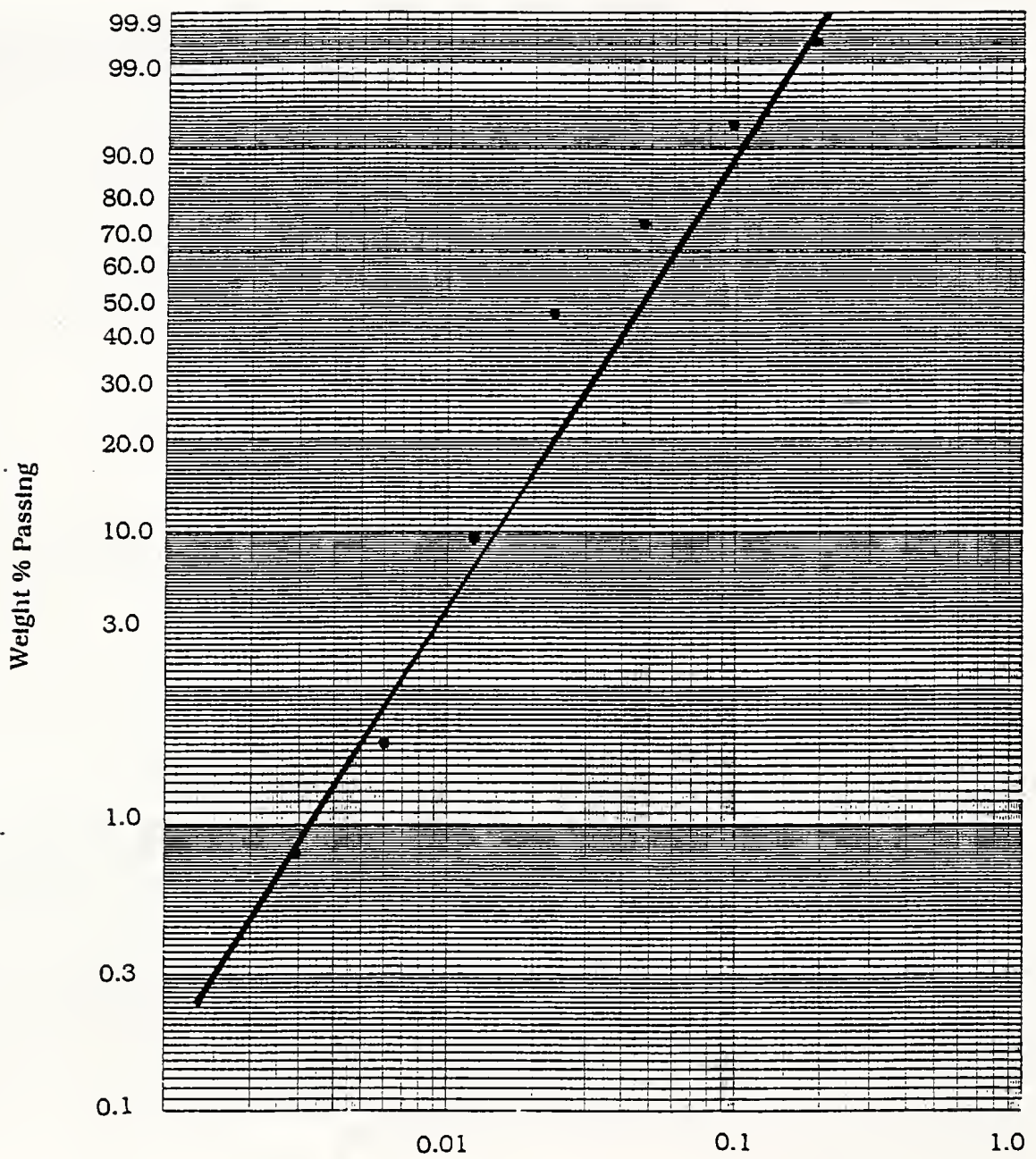

Particle size

Figure 5.1 I Plot of Fine Aggregate Sieve Analysis for Indianapolis Project 
Table 5.8 Mix Designs for Indianapolis Project

Field mix design

\begin{tabular}{|l|l|}
\hline & $\mathrm{lbs} / \mathrm{yd}^{3}$ \\
\hline Cement & 440 \\
\hline Fly Ash & 90 \\
\hline Water & 210 \\
\hline Fine Aggregate & 1280 \\
\hline Coarse Aggregate & 1845 \\
\hline AEA (oz $\left./ \mathrm{yd}^{3}\right)$ & 14 \\
\hline WRA (oz $/ \mathrm{yd}^{3}$ ) & 18 \\
\hline
\end{tabular}

Packing Handbook mix design

\begin{tabular}{|l|l|}
\hline & $\mathrm{lbs} / \mathrm{yd}^{3}$ \\
\hline Cement & 440 \\
\hline Fly Ash & 90 \\
\hline Water & 210 \\
\hline Fine Aggregate & 750 \\
\hline Coarse Aggregate & 2380 \\
\hline AEA (oz/yd 3 ) & 14 \\
\hline WRA (oz/yd 3 ) & 18 \\
\hline
\end{tabular}


Indianapolis Mix Design

Field vs. Packing Handbook

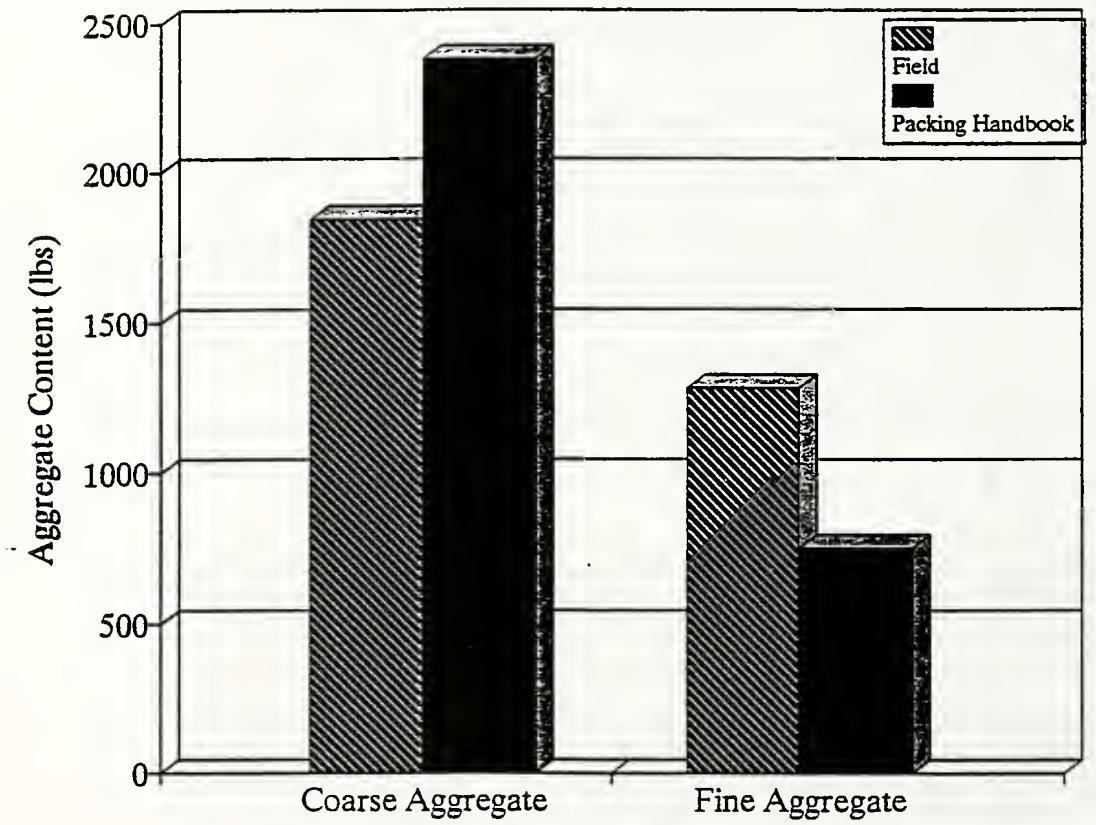

Figure 5.12 Aggregate Contents for Indianapolis Project 
Table 5.9 Sieve Analysis Used for South Bend Mix Design

Coarse Aggregate

\begin{tabular}{|c|c|}
\hline Sieve Size & Percent Passing \\
\hline \hline 1 in. & 100 \\
\hline $3 / 4$ in. & 98.7 \\
\hline $1 / 2$ in. & 74.5 \\
\hline $3 / 8$ in. & 45.4 \\
\hline$\# 4$ & 5.4 \\
\hline$\# 8$ & 1.2 \\
\hline
\end{tabular}

Fine Aggregate

\begin{tabular}{|c|c|}
\hline Sieve Size & Percent Passing \\
\hline \hline $3 / 8$ in. & 100 \\
\hline$\# 4$ & 99.0 \\
\hline$\# 8$ & 92.1 \\
\hline$\# 16$ & 78.9 \\
\hline$\# 30$ & 56.6 \\
\hline$\# 50$ & 2.4 \\
\hline$\# 100$ & 0.8 \\
\hline$\# 200$ & 0.3 \\
\hline
\end{tabular}




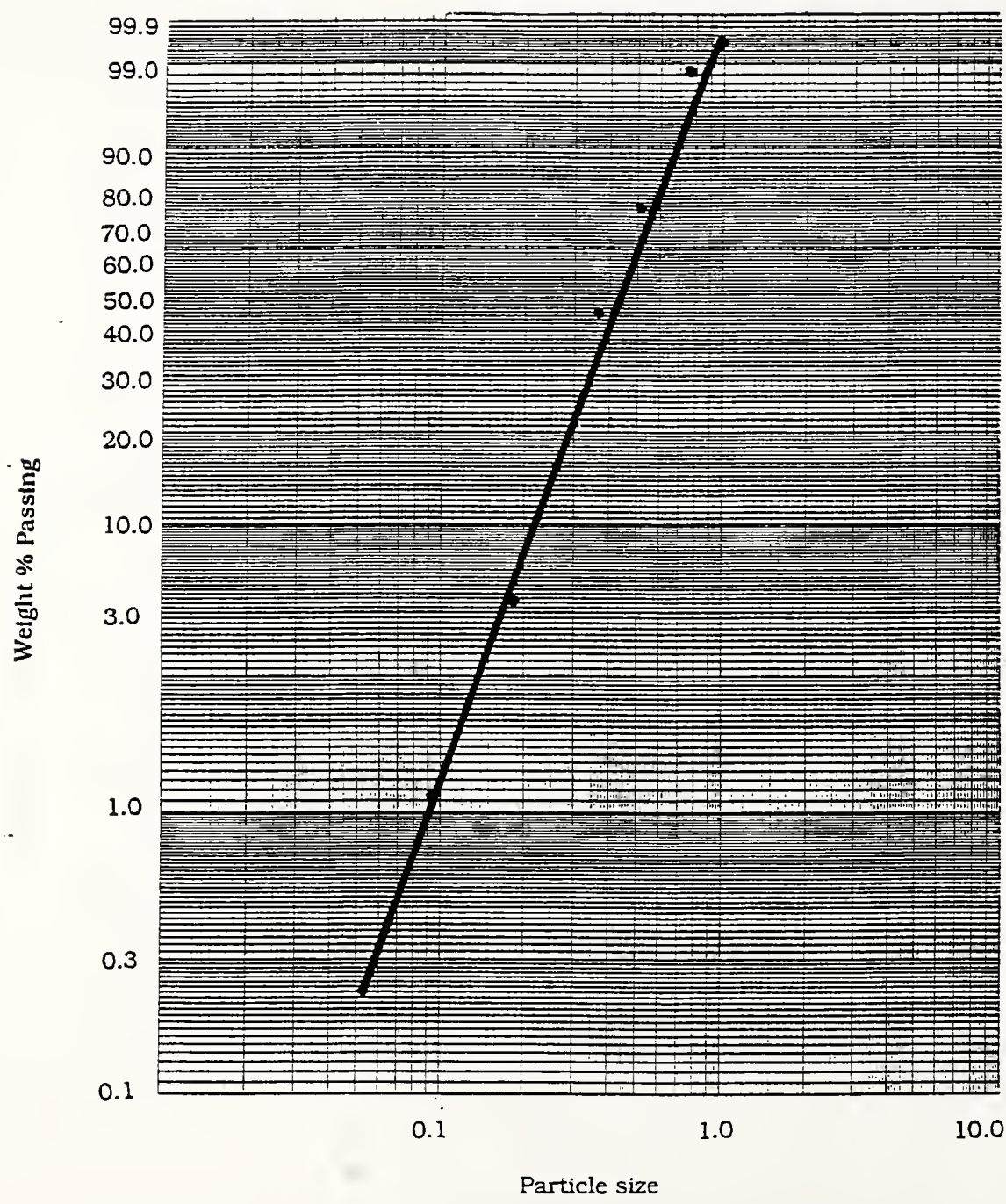

Figure 5.13 Plot of Coarse Aggregate Sieve Analysis for South Bend Project 


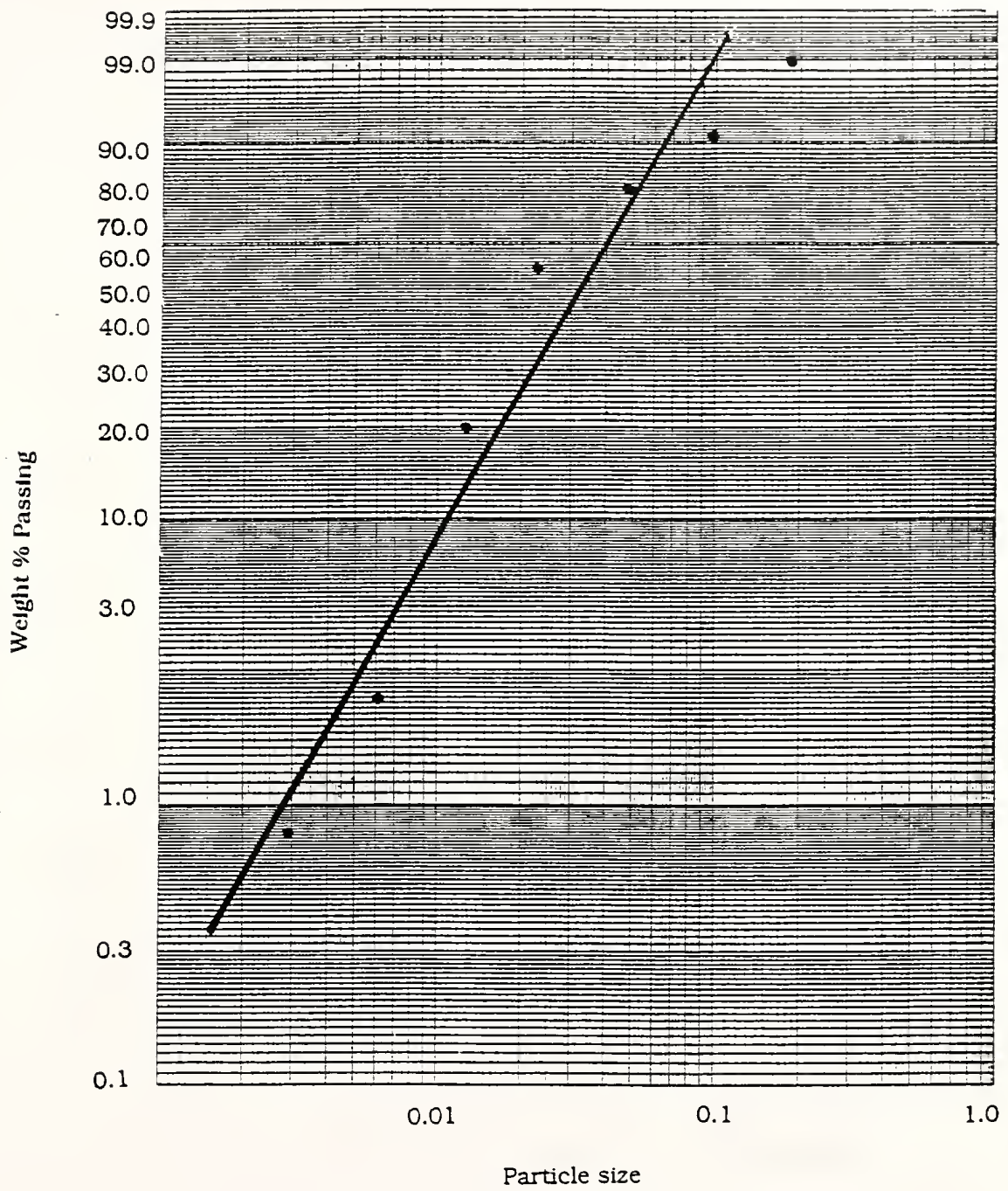

Figure 5.14 Plot of Fine Aggregate Sieve Analysis for South Bend Project 
Table 5.10 Mix Designs for South Bend Project

Field mix design

\begin{tabular}{|l|l|}
\hline & $\mathrm{lbs} / \mathrm{yd}^{3}$ \\
\hline Cement & 508 \\
\hline Fly Ash & 56 \\
\hline Water & 232 \\
\hline Fine Aggregate & 1265 \\
\hline Coarse Aggregate & 1745 \\
\hline AEA (oz/yd ${ }^{3}$ ) & 5 \\
\hline WRA (oz/yd ${ }^{3}$ ) & 15 \\
\hline
\end{tabular}

Packing Handbook mix design

\begin{tabular}{|l|l|}
\hline & $\mathrm{lbs} / \mathrm{yd}^{3}$ \\
\hline Cement & 508 \\
\hline Fly Ash & 56 \\
\hline Water & 232 \\
\hline Fine Aggregate & 1113 \\
\hline Coarse Aggregate & 1993 \\
\hline AEA (oz/yd 3 ) & 5 \\
\hline WRA (oz/yd 3 ) & 15 \\
\hline
\end{tabular}


South Bend Mix Design

Field vs. Packing Handbook

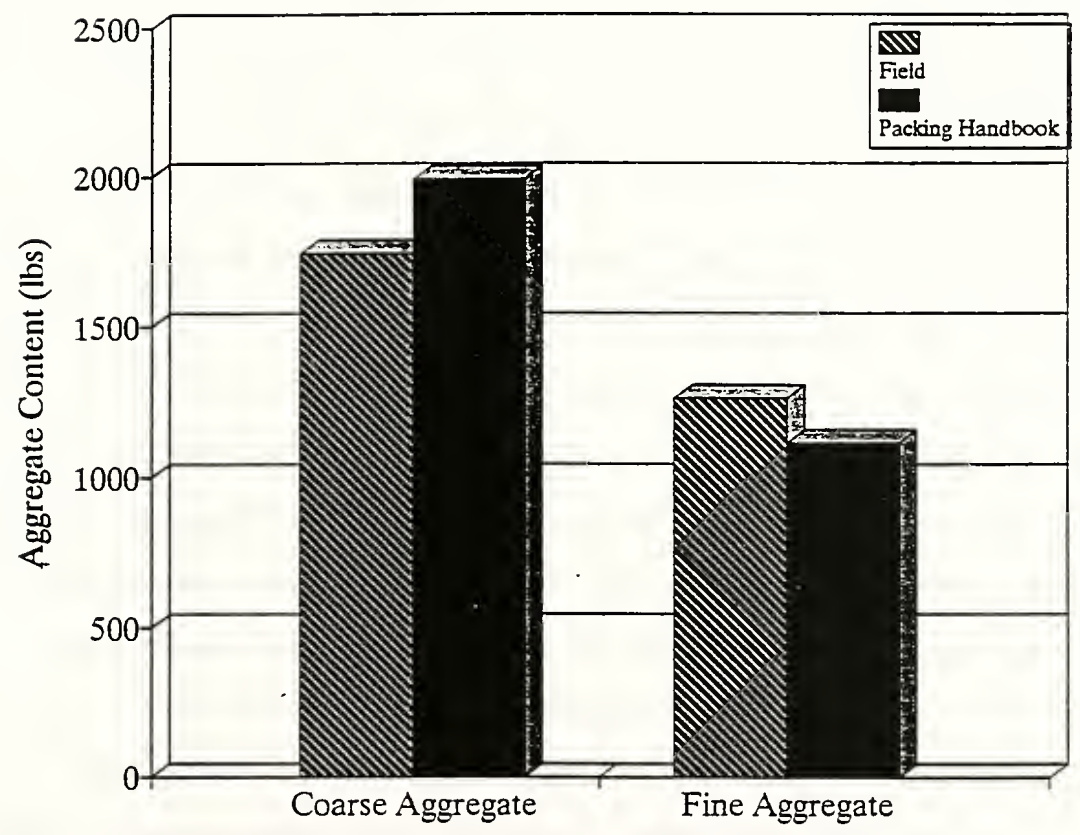

Figure 5.15 Aggregate Contents for South Bend Project 


\subsection{Concrete Properties}

In order to evaluate the Packing Handbook trial batches were prepared. For each project a minimum of three trial batches were conducted for both the Packing Handbook and field mix designs. For each trial batch a number of concrete properties were determined. The slump, air content, and unit weight of each trial batch was recorded. For each project the workability was visually appraised and noted for both the Packing Handbook and field proportioned mixes. Finally after curing for 7 days the specimens cast at mixing were tested and the flexural strengths recorded.

The results of the tests performed on the laboratory produced field and Packing Handbook mixes were compared to each other and results from the field. The field values were obtained from concrete quality assurance records and contractor records for each project $[37,38,39,40,41]$. The results of the slump test for both mixes in each project were averaged and plotted in Figure 5.16. The results of the air content tests were also averaged and are plotted in Figure 5.17. The average of the unit weight tests for the laboratory and field mixes are plotted in Figure 5.18. Finally, Figure 5.19 plots the results of flexural strength tests.

\subsubsection{Washington}

The results of trial batches for the Washington project are shown in Table 5.11. The field proportioned mix was easily placed and consolidated in the beam forms. The mixes proportioned with the Packing Handbook were harsh and were noticeably stiffer than field proportioned mixes. The placement and consolidation of the Packing Handbook mixes was possible, but required more effort than field mixes. Finishing was also more difficult with the Packing Handbook mixes. More effort was necessary to provide a smooth surface due to lower mortar contents. 
The slump of the Packing Handbook mix was on average more than an inch less the laboratory field mix. Air contents and unit weights were also lower for the Packing Handbook mix. The average flexural strength for the Packing Handbook mix was 5 percent higher than the average flexural strength of the field mixes.

\subsubsection{Elkhart}

Table 5.12 gives the results of the trial batches with aggregates used on the Elkhart project. The field proportioned mix exhibited excellent workability. The mix was easily placed and finished. The Packing Handbook proportioned mixes were also placed without difficulty. The Packing Handbook proportioned mixes were more harsh and stiff than the field proportioned mixes. Packing Handbook mixes were also more difficult to finish and more time was necessary to achieve a smooth uniform surface.

The slump of the field mix averaged an inch more than that of the Packing Handbook mix. The air content of the Packing Handbook mix was 1.1 percent higher than the mean field air content. This contributed to higher unit weight of the Packing Handbook mix. Finally, an average increase of 13 percent in strength was shown for the mix proportioned with the Packing Handbook.

\subsubsection{Greenfield}

The results from the mixes with aggregate from the Greenfield project were similar to the other projects using crushed limestone as the coarse aggregate. The results of the trial batches are given in Table 5.13. The water reducing admixture was accidentally omitted in batch 1 for the field proportioned mixes. Additionally water was required to get a reasonable slump and the $\mathrm{w} / \mathrm{c}$ exceeded the field value of 0.37 . Batch 2 of the field proportioned mix and batch 1 of the Packing Handbook mix contained both the additional water and water reducing admixture. The slumps for these trial batches 
were therefore higher than expected. The situation was corrected. The proper water content and admixture dosages were used for the final two trial batches of both the field and Packing Handbook proportioned mixes

The workability of field mix was excellent and no problems with placement consolidation or finishing were encountered. The mix proportioned with the aid of the Packing Handbook was also placed and fininshed but again with more difficulty than the field proportioned mix.

The Packing Handbook mix designed with the Greenfield project aggregates had slumps only $1 / 4$ inch less than the field mix. The average air content was almost 2 percent less than the field proportioned mix. The unit weight of the Packing Handbook mix was also higher. Flexural Strengths were increased by 10 percent with the Packing Handbook mix.

\subsubsection{Indianapolis}

The results of the trial batches of both the field proportioned and Packing Handbook proportioned mixes is shown in Table 5.14. The workability of the field proportioned mixes was very good. The rounded shape of the gravel coarse aggregate made this mix easier to place and finish than the field mixes from other projects with angular coarse aggregate. Some problems developed with the placement and consolidation of the Packing Handbook proportioned mix. The low slump and dry consistency of the mixes resulted in mild segregation in some of the specimens. The Packing Handbook mix was also difficult to finish despite the favorable particle shape.

A difference of over 1.5 inches in the average slump was recorded for the Packing Handbook and field mixes. Average air content dropped by over 2 percent for the Packing Handbook mix. Consequently the unit weight of the Packing Handbook mix 
was higher. And increase of 3 percent was achieved in the average flexural strength of the Packing Handbook mix over the field mix.

\subsubsection{South Bend}

The South Bend project used slag as a coarse aggregate. The results of the trial batches are given in Table 5.15. The field proportioned mix was easily placed and consolidated. Some difficulty was encountered in finishing the mix. The slag had a tendency to rise to the top of the specimen due to its low specific gravity. The problem was partially solved with the saturation of the coarse aggregate prior to mixing. The finishing improved but more effort was required than had previously been necessary for other coarse aggregate types. The mix proportioned with the Packing Handbook had lower workability than the field proportioned mix. The Packing Handbook mix was more difficult to consolidate. The finishing problems encountered with the field mix were even worse with the Packing Handbook mixes. This was due to the combination of less mortar and a higher percentage of aggregate that tended to rise to the top of the specimen.

The average slump for the Packing Handbook mix was only $1 / 2$ an inch. The slump of the laboratory produced field mix averaged slightly more than $13 / 4$ inches. Air content was only 0.5 percent lower for the Packing Handbook mix. The average unit weights were nearly identical. A 6 percent increase in flexural strength average was obtained with the Packing Handbook mix. 
Field vs. Packing Handbook

Slump

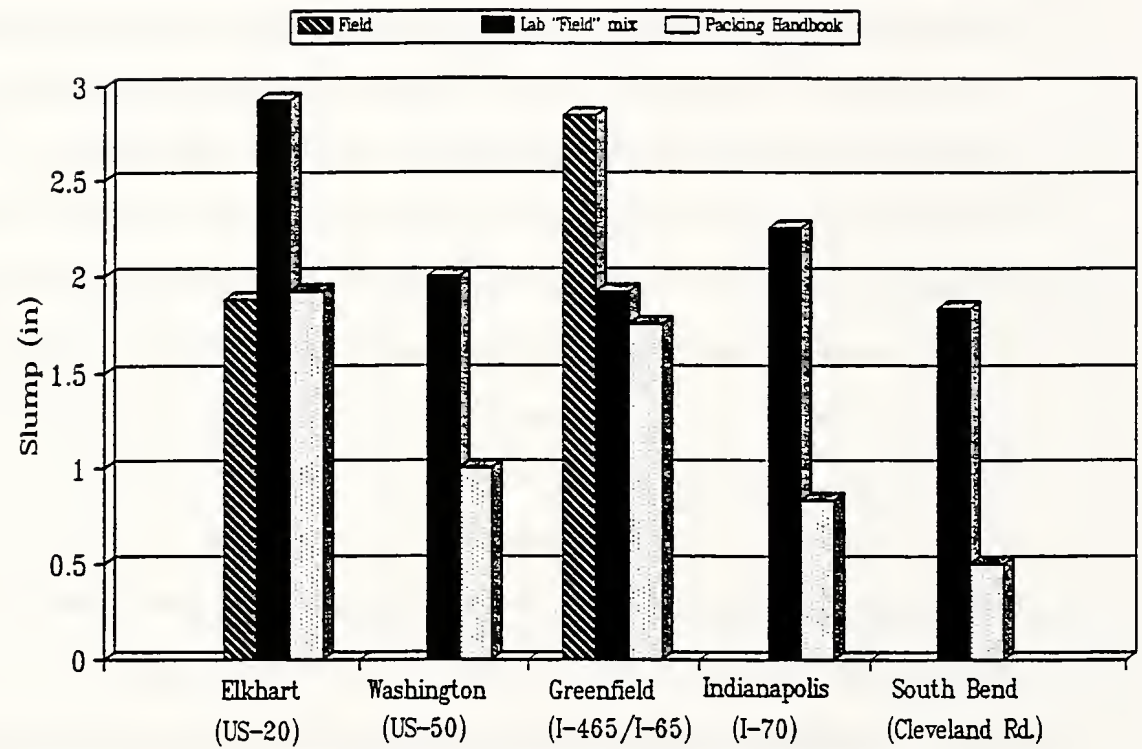

Note No Slump Data trom Field for Washington Indiamapolis and South Bend 
Field rs Packing Handbook Air Content

AIV Field Lab "Tieid" mix $\square$ Pacing Handbook

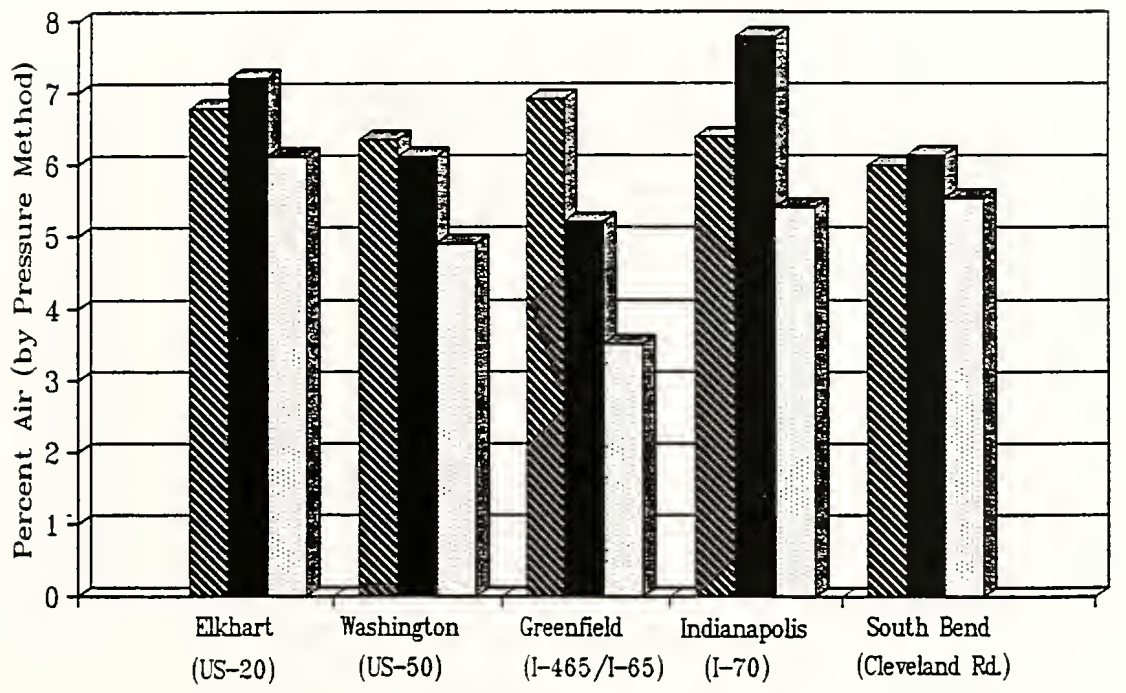

Figure 5.17 Air Content of Packing Handbook and Field Proportioned Mixes 
Field vs Packing Handbook Unit Weight

MV Field Lab "Feld" mix $\square$ Packeng Handbook

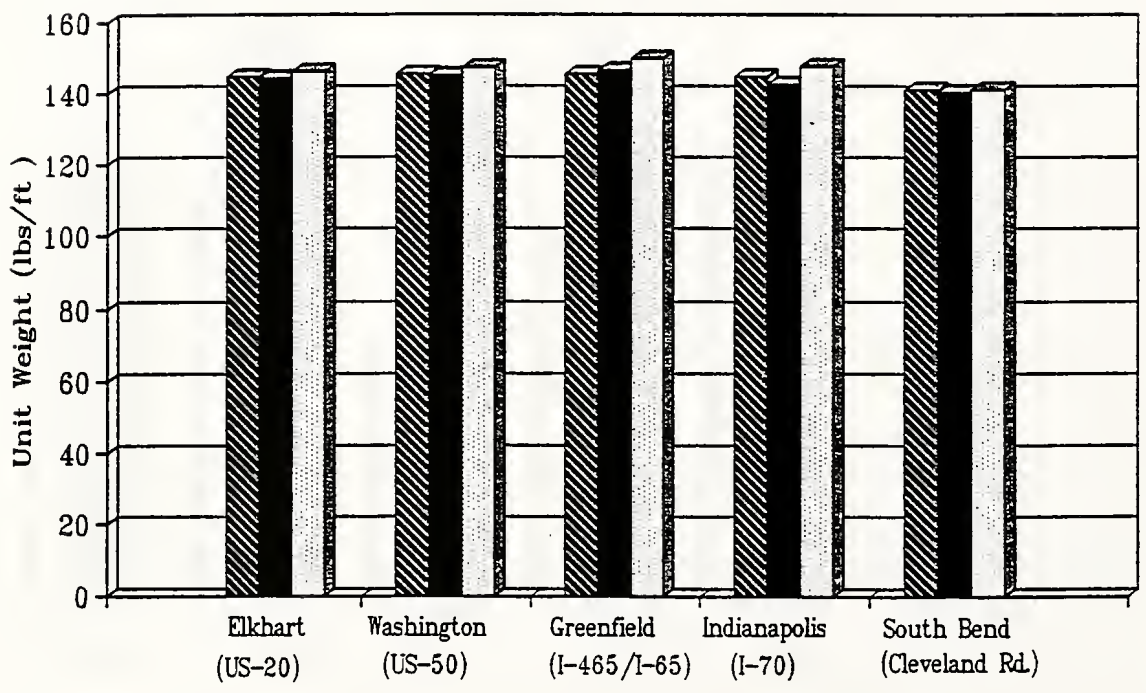

Figure 5.18 Unit Weight of Packing Handbook and Field Proportioned Mixes 
Field vS. Packing Handbook

Flexural Strength

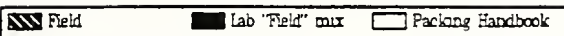

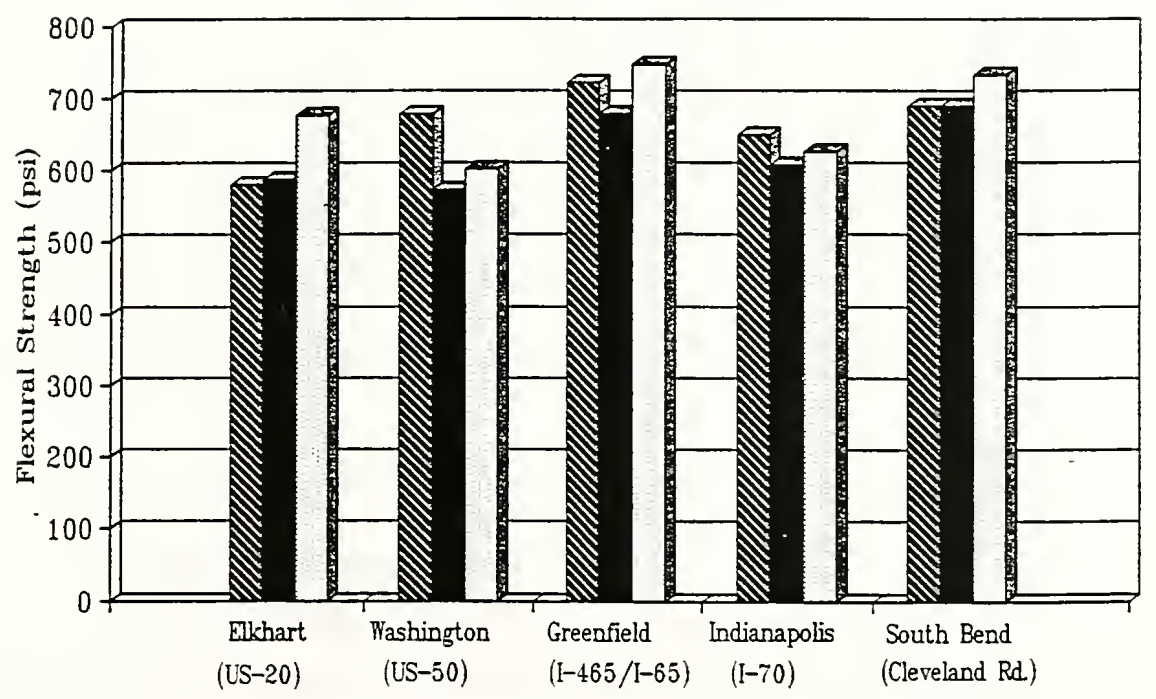

Figure 5.19 Flexural Strength of Packing Handbook and Field Proportioned Mixes 
Table 5.11 Concrete Properties for Trial Batches with Aggregates from Washington Project

Laboratory "field" batch results

\begin{tabular}{|l|l|l|l|}
\hline & Batch 1 & Batch 2 & Batch 3 \\
\hline Date & $10 / 07 / 92$ & $10 / 27 / 92$ & $11 / 13 / 92$ \\
\hline W/C & 0.43 & 0.43 & 0.43 \\
\hline Slump (in) & 2 & 2 & 6.5 \\
\hline Air content (\%) & 7.0 & 5.6 & 5.7 \\
\hline Unit wt (lbs $/ \mathrm{ft}^{3}$ ) & 145 & 145.6 & 144 \\
\hline Yield (ft ${ }^{3}$ ) & 27.3 & 27.1 & 27.4 \\
\hline Ave. $\mathrm{F}_{\mathrm{h}}$ (psi) & 580 & 620 & 515 \\
\hline
\end{tabular}

Laboratory Packing Handbook batch results

\begin{tabular}{|l|l|l|l|}
\hline & Batch 1 & Batch 2 & Batch 3 \\
\hline Date & $10 / 07 / 92$ & $10 / 27 / 92$ & $11 / 13 / 92$ \\
\hline $\mathrm{W} / \mathrm{C}$ & 0.43 & 0.43 & 0.39 \\
\hline Slump (in) & 0.75 & 0.75 & 1.5 \\
\hline Air content (\%) & 4.5 & 5.0 & 5.3 \\
\hline Unit wt (lbs/ft ${ }^{3}$ ) & 148 & 147.2 & 146.4 \\
\hline Yield (ft ${ }^{3}$ ) & 26.7 & 26.8 & 27 \\
\hline Ave. $F^{\prime}$ (psi) & 615 & 615 & 565 \\
\hline
\end{tabular}


Table 5.12 Concrete Properties for Trial Batches with Aggregates from Elkhart Project

Laboratory "field" batch results

\begin{tabular}{|l|l|l|l|}
\hline & Batch 1 & Batch 2 & Batch 3 \\
\hline Date & $10 / 16 / 92$ & $10 / 28 / 92$ & $11 / 12 / 92$ \\
\hline $\mathrm{W} / \mathrm{C}$ & 0.36 & 0.33 & 0.4 \\
\hline Slump (in) & 2.25 & 2.5 & 4 \\
\hline Air content (\%) & 7.4 & 7.8 & 6.4 \\
\hline Unit wt (lbs/ $\mathrm{ft}^{3}$ ) & 144.8 & 144.0 & 144 \\
\hline Yield (ft ${ }^{3}$ ) & 26.8 & 26.9 & 26.9 \\
\hline Ave. $\mathrm{F}_{\mathrm{h}}^{\prime}$ (psi) & 600 & 595 & 625 \\
\hline
\end{tabular}

Laboratory Packing Handbook batch results

\begin{tabular}{|l|l|l|l|}
\hline & Batch 1 & Batch 2 & Batch 3 \\
\hline Date & $10 / 8$ & $10 / 28 / 92$ & $11 / 12 / 92$ \\
\hline $\mathrm{W} / \mathrm{C}$ & 0.31 & 0.33 & 0.34 \\
\hline Slump (in) & 1 & 1.75 & 3 \\
\hline Air content (\%) & 5.4 & 6.2 & 6.6 \\
\hline Unit wt (lbs/ft ${ }^{3}$ ) & 147.2 & 147.2 & 143.2 \\
\hline Yield (ft $\left.{ }^{3}\right)$ & 26.3 & 26.3 & 27.1 \\
\hline Ave. $F^{\prime}{ }^{\prime}(\mathrm{psi})$ & 810 & 610 & 580 \\
\hline
\end{tabular}


Table 5.13 Concrete Properties for Trial Batches with Aggregates from Greenfield Project

Laboratory "field" batch results

\begin{tabular}{|l|l|l|l|l|}
\hline & Batch 1 & Batch 2 & Batch 3 & Batch 4 \\
\hline Date & $10 / 6 / 92$ & $11 / 3 / 92$ & $11 / 4 / 92$ & $11 / 5 / 92$ \\
\hline W/C & 0.41 & 0.41 & 0.36 & 0.37 \\
\hline Slump (in) & 1.25 & 7.5 & 1.5 & 3 \\
\hline Air content (\%) & 2.3 & 8 & 4.9 & 5.7 \\
\hline Unit wt (lbs/ft $\left.{ }^{3}\right)$ & 151.6 & 141.2 & 147.6 & 145.6 \\
\hline Yield (ft 3 ) & 26.3 & 28.2 & 26.9 & 27.2 \\
\hline Ave. $F_{b}{ }^{3}(\mathrm{psi})$ & 750 & 550 & 730 & 650 \\
\hline
\end{tabular}

Laboratory Packing Handbook batch results

\begin{tabular}{|l|l|l|l|}
\hline & Batch 1 & Batch 2 & Batch 3 \\
\hline Date & $10 / 6 / 92$ & $11 / 3 / 92$ & $11 / 5 / 92$ \\
\hline W/C & 0.41 & 0.35 & 0.37 \\
\hline Slump (in) & 2.75 & 1 & 1.5 \\
\hline Air content (\%) & 3.3 & 3.0 & 4.2 \\
\hline Unit wt (lbs/ft $\left.{ }^{3}\right)$ & 149.60 & 151.2 & 148.4 \\
\hline & & 26.1 & 26.8 \\
\hline Yield (ft & & & 715 \\
\hline Ave. $F^{\prime}{ }^{3}(\mathrm{psi})$ & 745 & 780 & \\
\hline
\end{tabular}


Table 5.14 Concrete Properties for Trial Batches with Aggregates from Indianapolis Project

Laboratory "field" batch results

\begin{tabular}{|l|l|l|l|l|}
\hline & Batch 1 & Batch 2 & Batch 3 & Batch 4 \\
\hline Date & $1 / 22 / 93$ & $1 / 26 / 93$ & $1 / 28 / 93$ & $2 / 9 / 93$ \\
\hline $\mathrm{W} / \mathrm{C}$ & 0.47 & 0.39 & 0.39 & 0.39 \\
\hline Slump (in) & 6.5 & 1.75 & 1.75 & 3.25 \\
\hline Air content (\%) & 8.0 & 9.5 & 6.4 & 7.4 \\
\hline Unit wt (lbs/ft ${ }^{3}$ ) & 141.6 & 140 & 145.2 & 142.4 \\
\hline Yield (ft ${ }^{3}$ ) & 27.3 & 27.6 & 26.6 & 27.1 \\
\hline Ave. $F_{b}^{\prime}$ (psi) & 485 & 530 & 685 & 600 \\
\hline
\end{tabular}

Laboratory Packing Handbook batch results

\begin{tabular}{|l|l|l|l|l|}
\hline & Batch 1 & Batch 2 & Batch 3 & Batch 4 \\
\hline Date & $1 / 22 / 93$ & $1 / 26 / 93$ & $1 / 28 / 93$ & $2 / 9 / 93$ \\
\hline W/C & 0.32 & 0.39 & 0.39 & 0.39 \\
\hline Slump (in) & 0 & 1 & 0.5 & 1 \\
\hline Air content (\%) & 2.8 & 6.8 & 3.9 & 5.5 \\
\hline Unit wt (lbs/ft ${ }^{3}$ ) & 151.6 & 145.6 & 149.6 & 147.2 \\
\hline Yield (ft ${ }^{3}$ ) & 25.5 & 26.6 & 25.9 & 26.3 \\
\hline Ave. F' ${ }^{\prime}$ (psi) & 775 & 540 & 705 & 630 \\
\hline
\end{tabular}


Table 5.15 Concrete Properties for Trial Batches with Aggregates from South Bend Project

Laboratory "field" batch results

\begin{tabular}{|l|l|l|l|}
\hline & Batch 1 & Batch 2 & Batch 3 \\
\hline Date & $6 / 10 / 93$ & $6 / 17 / 93$ & $6 / 24 / 93$ \\
\hline $\mathrm{W} / \mathrm{C}$ & 0.41 & 0.41 & 0.41 \\
\hline Slump (in) & 1.5 & 2 & 2 \\
\hline Air content (\%) & 6.0 & 6.0 & 6.4 \\
\hline Unit wt (lbs/ft ${ }^{3}$ ) & 140.8 & 140.8 & 139.2 \\
\hline Yield (ft ${ }^{3}$ ) & 27.0 & 27.0 & 27.3 \\
\hline Ave. $\mathrm{F}_{\mathrm{h}}$ (psi) & 753.5 & 662 & 650 \\
\hline
\end{tabular}

Laboratory Packing Handbook batch results

\begin{tabular}{|l|l|l|l|}
\hline & Batch 1 & Batch 2 & Batch 3 \\
\hline Date & $6 / 10 / 93$ & $6 / 17 / 93$ & $6 / 24 / 93$ \\
\hline $\mathrm{W} / \mathrm{C}$ & 0.41 & 0.41 & 0.41 \\
\hline Slump (in) & 0.25 & 0.75 & 0.5 \\
\hline Air content (\%) & 5.0 & 5.6 & 6.0 \\
\hline Unit wt (lbs/ $\mathrm{ft}^{3}$ ) & 142.4 & 140.8 & 139.6 \\
\hline Yield (ft ${ }^{3}$ ) & 27.4 & 27.7 & 27.9 \\
\hline Ave. $\mathrm{F}_{\mathrm{b}}$ (psi) & 776 & 709 & 712 \\
\hline
\end{tabular}




\section{$\underline{5.3 \mathrm{~W} / \mathrm{C} \text { Study }}$}

In addition to the testing on different aggregate types, testing was done to determine how the Packing Handbook aggregate proportioning method responded to different $w / c$. Previously the $w / c$ had been held constant with values used on field projects. An interest was expressed to find out how the Packing Handbook aggregate proportioned mixes compared to mixes with field aggregate proportions at other w/c. For this study the $w / c$ varied and the cement content was held constant at 600 $\mathrm{lbs} / \mathrm{yd}^{3}$. The water content was then varied to give $\mathrm{w} / \mathrm{c}$ of $0.35,0.40,0.45$, and 0.50 . For $w / c$ of 0.35 , and 0.40 the water reducing admixture dosages were adjusted to give slumps that were judged to be pavable. For $w / c$ of 0.45 and 0.50 the dosage was adjusted so that both the field and Packing Handbook mixes had approximately the same slump. Aggregate relative proportions were established from the Packing Handbook and field mixes using the same aggregates. The ratio of coarse aggregate to total aggregate was .72 for the Packing Handbook Mixes and .61 for the field mixes. The total quantity of aggregate used was adjusted to occupy the remaining unit volume not occupied by the paste. Air entraining admixture dosages were adjusted to the achieve a satisfactory air content and slump. The mix designs prepared are shown in Table 5.16.

The trial batches were prepared and flexural beams were cast from each mix at the facilities of Rieth-Riley Construction in Goshen, IN. Table 5.17 shows the results of tests performed on the trial batches. The results of these trial batches indicate that the strength of mixes proportioned using the Packing Handbook were actually lower than the field mixes at a given w/c. This is the opposite of the trend observed in the laboratory at Purdue. Their are two possible explanations for this discrepancy. First, these batches were mixed with a different mixer than the laboratory mixes at Purdue. More importantly the slump and air contents were controlled to levels suitable for paving by varying the dosages of admixtures. The slump and air content for the 
Packing Handbook and field proportioned mixes was held as constant as possible. In the lab the admixture dosages were held constant and the slump and air content differences noted. It appears that at a constant w/c. slump, and air content use of the Packing Handbook does not result in higher strengths. It should also be noted that Packing Handbook mixes were more difficult to finish even when the slump was the same as field mixes. 
Table 5.16 Mix Designs for W/C Study

\begin{tabular}{|c|c|c|c|c|c|c|c|}
\hline Mix No. & $\mathrm{w} / \mathrm{c}$ & $\begin{array}{c}\mathrm{CA} / \mathrm{TA} \\
(\%)\end{array}$ & $\begin{array}{c}\text { Cement } \\
\left(\mathrm{lbs} / \mathrm{yd}^{3}\right)\end{array}$ & $\begin{array}{c}\text { Water } \\
\left(\mathrm{lbs} / \mathrm{yd}^{3}\right)\end{array}$ & $\begin{array}{c}\text { FA (ssd) } \\
\left(\mathrm{lbs} / \mathrm{yd}^{3}\right)\end{array}$ & $\begin{array}{c}\text { CA (ssd) } \\
\left(\mathrm{lbs} / \mathrm{yd}^{3}\right)\end{array}$ & $\begin{array}{c}\text { WRA } \\
\left(\mathrm{oz} / \mathrm{yd}^{3}\right)\end{array}$ \\
\hline 1 & 0.35 & 0.61 & 600 & 210 & 1209 & 1918 & 18 \\
\hline 2 & 0.35 & 0.72 & 600 & 210 & 868 & 2265 & 18 \\
\hline 4 & 0.40 & 0.72 & 600 & 240 & 845 & 2207 & 18 \\
\hline 5 & 0.35 & 0.61 & 600 & 210 & 1209 & 1919 & 34.2 \\
\hline 6 & 0.35 & 0.72 & 600 & 210 & 868 & 2265 & 34.2 \\
\hline 7 & 0.40 & 0.61 & 600 & 240 & 1178 & 1869 & 10.44 \\
\hline 8 & 0.40 & 0.72 & 600 & 240 & 845 & 2207 & 16.2 \\
\hline 9 & 0.45 & 0.61 & 600 & 270 & 1157 & 1821 & 10.5 \\
\hline 10 & 0.45 & 0.72 & 600 & 270 & 831 & 2149 & 0 \\
\hline 11 & 0.50 & 0.61 & 600 & 300 & 1126 & 1772 & 0 \\
\hline 12 & 0.50 & 0.72 & 600 & 300 & 809 & 2091 & 0 \\
\hline
\end{tabular}


Table 5.17 Results of Trial Batches for W/C Study

\begin{tabular}{|c|c|c|c|c|c|c|c|}
\hline Mix No. & Slump & Unit Wt & Yield & Air & \multicolumn{3}{|c|}{ Flexural Strength (psi) } \\
\hline & (in) & $\left(\mathrm{lbs} / \mathrm{ft}^{3}\right)$ & $\left(\mathrm{ft}^{3}\right)$ & $(\%)$ & Beam 1 & Beam 2 & Ave. \\
\hline 1 & 1 & 149.12 & 26.41 & 4.7 & 816 & 816 & 816 \\
\hline 2 & 1 & 151.32 & 26.06 & 3.6 & 800 & 825 & 812 \\
\hline 4 & 2 & 144.60 & 26.93 & 5.9 & 637 & 641 & 639 \\
\hline 5 & 1.5 & 147.50 & 26.71 & 5.7 & 766 & 875 & 820 \\
\hline 6 & 1.5 & 146.12 & 26.99 & 6.0 & 743 & 767 & 755 \\
\hline 7 & 1.5 & 145.48 & 26.78 & 6.2 & 685 & 719 & 702 \\
\hline 8 & 1.5 & 144.40 & 26.96 & 6.5 & 657 & 615 & 636 \\
\hline 9 & 7.25 & 139.20 & 26.64 & 9.2 & 549 & & 549 \\
\hline 10 & 8 & 140.80 & 27.34 & 7.7 & 561 & & 561 \\
\hline 11 & 10 & 140.00 & 27.13 & 8.2 & 536 & & 536 \\
\hline 12 & 10 & 141.60 & 26.84 & 6.2 & 491 & & 491 \\
\hline
\end{tabular}




\section{W/C vs. Flexural Strength}

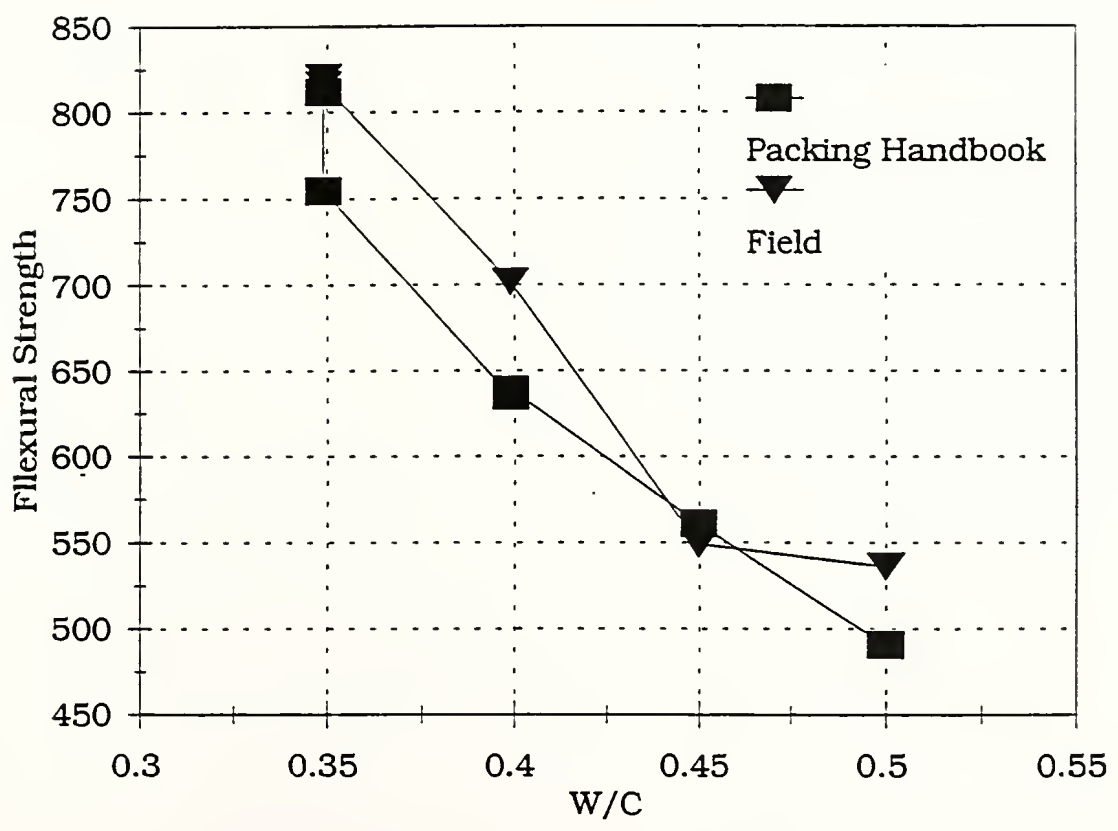

Figure 5.20 W/C vs. Strength for Water Cement Study 


\section{$\underline{5.4 \text { Air Void Tests }}$}

Air void analysis of 2 specimens was conducted. The purpose of the air void analysis was to determine if the air void system in a Packing Handbook mix with low air content was adequate. Air void analysis was also done on a laboratory field proportioned mix to determine if the air content was excessive. An air void specimen was removed from a beam cast during trial batch 2 for the Packing Handbook proportioned mix on the Greenfield project. The measured air content for the fresh concrete from this trial batch was 3.0 percent. The field proportioned mix specimen was removed from a beam cast during trial batch 2 on the Greenfield project. The air content of the fresh concrete for this batch was recorded at 8.0 percent.

The results of the air void analysis are given in Table 5.18. The air content of the hardened concrete for the Packing Handbook specimen was 3.06 percent. This is in close agreement with the value recorded for the fresh paste. The Powers spacing factor for this specimen was 0.008 in.. This spacing is marginally adequate protection for frost protection. The air content of the hardened field proportioned specimen was 9.49 percent. This is nearly 1.5 percent higher than the value calculated when the beam was cast. The Powers spacing factor for this specimen is $0.0030 \mathrm{in}$. The spacing factor for properly air entrained concrete is usually in the range of 0.008 to 0.004 in. 
Table 5.18 Air Void Analysis of a Packing Handbook and Field Trial Batch

\begin{tabular}{|l|r|r|}
\hline Specimen & $\begin{array}{r}\text { Packing Handbook } \\
\text { mix }\end{array}$ & Field mix \\
\hline Air content & 3.06 & 9.49 \\
\hline Length of traverse (in.) & 310.9 & 329.4 \\
\hline Number of stops & 3165 & 3325 \\
\hline Number of voids/in & 5.35 & 16.61 \\
\hline Powers spacing factor & 0.008 in. $(200 \mu \mathrm{m})$ & 0.003 in. $(70 \mu \mathrm{m})$ \\
\hline
\end{tabular}




\section{SUMMARY AND CONCLUSIONS}

The goal of this research was to determine what benefits result with the use of the Packing Handbook. The research was the subject of a previously published paper [52] and a internal interim reports. For the Packing Handbook to be implemented it should be easy to use and apply to a variety of materials. Implementation also would depend on the properties of fresh and hardened concrete produced with the aid of the Packing Handbook. Finally, there must be an economic incentive to use the Packing Handbook.

The procedure outlined in the Packing Handbook is easy to learn but a few problems were encountered. The plotting of sieve analysis points on Rosin-Rammler graph paper is tedious. Unfortunately automating the plotting with conventional spreadsheet software is difficult or impossible due to the $\log \log$ scale on the $y$-axis. The sieve analysis points do not always fit a linear distribution on the Rosin-Rammler graph paper. Regression analysis would be very difficult again due to the nature of the axis scale. For this research the sieve analyses were plotted manually and the lines fitted through the points visually. Since the sieve analysis data are not always linear some subjectivity is involved in obtaining characteristic diameters. Fortunately the Packing Handbook tables are not highly sensitive to slight differences in the characteristic diameter. The other parameter needed for each aggregate is the packing density. This parameter is easily found by determining the percent voids for the dry rodded aggregates. 
Mixes proportioned with the aid of the Packing Handbook had some workability problems. The mixes were all more harsh than mixes with field proportions. Packing Handbook mixes required more effort to consolidate in the beam forms. Adequate consolidation was achieved for all mixes in the laboratory. If the Packing Handbook mixes were used in the field consolidation problems may be experienced. Packing Handbook mixes used for paving may be able placed, but proper consolidation may be extremely difficult if not impossible for concrete which is highly reinforced concrete, or areas where vibration can not be applied. Finishing of mixes proportioned with the Packing Handbook was difficult due to the lower mortar contents. Additional effort and time for finishing may be required if Packing Handbook mixes were used in the field.. Some surface textures may be especially difficult to achieve. Entraining air in Packing Handbook mixes was difficult. These mixes had lower sand contents and since sand is instrumental in acquiring air entrainment bubbles in concrete the dosage of air entraining admixtures had to be increased. Even with additional air entraining admixture, air contents were lower than field proportioned mixes.

The properties of the hardened concrete were also different for Packing Handbook and field mixes. Strengths were higher for Packing handbook mixes. This is in part due to the fact that these mixes had lower air contents. When the strength of laboratory produced field mixes is corrected by five percent for every 1 percent of higher air content the difference in flexural strength is minimal. When field proportioned mixes are corrected the strength of the Packing Handbook mixes is only 2.5 percent greater than the field mixes for the Washington and South Bend projects. The average flexural strength of the Packing Handbook mixes is still 7 percent higher for the trial batches using Elkhart project aggregates. However, when the same aggregates that were used on this project were used in the water to cement study the mixes with field proportions of aggregates had higher strengths. The average corrected strengths for the 
Greenfield project were nearly identical. The corrected strength of the Indianapolis project field proportioned mix was 7 percent higher than the average strength of the Packing Handbook mix. The difficulty in achieving air content in Packing Handbook mixes may lead to durability problems. Many of the trail batches had air contents less than 5.5 percent

The most common way to reduce the cost of concrete is to reduce the cement content. For mixes designed with the aid of the Packing Handbook the strength increases were not consistent or large enough to result in any reduction of cement content at a given strength. Cement contents may have to be increased to solve the workability problems associated with the Packing Handbook mixes. Since the Packing Handbook mixes consistently use more coarse aggregate they will be more expensive where the unit cost of coarse aggregate is higher than the unit cost of fine aggregate. If the fine aggregate is more expensive Packing Handbook mixes may be cheaper.

\section{$\underline{6.1 \text { Conclusions }}$}

1. The procedure outlined in the Packing Handbook to proportion aggregate for concrete is easy to learn. Plotting the sieve analysis on Rosin- Rammler graph paper is tedious and the determination of the characteristic diameter may not be entirely objective.

2. Packing Handbook mixes have lower workability than mixes currently being used in the field.

3. Air entrainment is difficult for some mixes produced with the Packing Handbook. This is a result of low sand contents for these mixes.

4. Strength increase with mixes proportioned with the Packing Handbook is minimal or non existent at constant air contents. 
5. Packing Handbook mixes may be difficult to handle and finish with present concrete pavers.

6. Little or no cost savings will be realized with the use of the Packing Handbook.

Cost savings may be realized if the relative cost of fine aggregate is less than the cost of coarse aggregate. 
LIST OF REFERENCES 


\section{LIST OF REFERENCES}

[1] ACI Standard 211.1-81, "Standard Practice for Selecting Proportions for Normal, Heavyweight and Mass Concrete," American Concrete Institute, 1981, pp. 4-10.

[2] Andersen, P. J., and Johansen, V., "Packing Handbook - A Guide to Determine the Optimal Gradation of Concrete Aggregates," SHRP Contract 206, Nov. 1991.

[3] Johansen, V., and Andersen, P. J., "Particle Packing and Concrete Properties," Materials Science of Concrete II., American Ceramic Society, 1990. pp. 111-147.

[4] ASTM C29M-90, "Standard Test Method for Unit Weight and Voids in Aggregate," Annual Book of Standards, ASTM, Philadelphia. Vol. 04.02, 1990.

[5] Fuller, W. B., and Thompson, S. E.. "The Laws of Proportioning Concrete," Transactions ASCE, V. 59, 1907, pp. 67-143.

[6] Talbot, A. N., "A Proposed Method of Estimating the Density and Strength of Concrete and of Proportioning the Materials by Experimental and Analytical Considerations of the Voids in Mortar and Concrete," Proceedings ASTM, Vol. 29. 1921. pp. 940-.

(7) Young, R. B., "Some Theoretical Studies on Proportioning Concrete by the Method of Surface Area Aggregate," Proceedings ASTM, Vol. 19, Part 2, 1919. pp.444-.

[8] Edwards, L. N., "Proportioning the Materials of Mortars and Concretes by Surface Areas of Aggregates," Proceedings ASTM, Vol. 18, Part 2, 1918, pp. 235.

[9] Abrams, D. A., "Design of Concrete Mixtures," Bulletin No. 1. Structural Materials Research Laboratory, Lewis Institute, Chicago, 1918.

[10] Cordon, W. A., "History of Concrete Proportioning," ACI SP-46, Proportioning of Concrete Mixes, American Concrete Institute, Detroit, MI., 1974, pp. 167-176.

(I1) Teychenne, D. C., Franklin, R. E., and Erntroy, H., "Design of Normal Conrete Mixes," Deparment of the Enviroment, London, H. M. S. O.. 1975.

[12] Tattersall, G. H., and Banfill.P. F. G., "The Rheology of Fresh Concrete," Pitman, London, 1983.

[13] Imbert, I., "Influence of the Grading of Aggregates on Concrete Mix Proportions," Highway Research Record 441. Transportation Research Board, Washington.

D. C., 1973, pp. 44-55. 
[14] Tattersall, G. H., "Workability and Quality Control of Concrete," E. \& F. N. Spon, London, 1991.

[15] Hughes, B. P., "Particle Interference and the Workability of Concrete," ACI Joumal Proceedings, Vol. 63, No. 3, March 1966, pp. 369-372.

[16] Hughes, B. P., The Optimum Coarse Aggregate Content for Concrete," Magazine of Concrete Research, Vol. 18, No. 54, March 1966, pp. 3-8.

[17] Hughes, B. P., "Rational Design of Concrete Mixes," Concrete, Vol. 2, No. 5, May 1968, pp. 212-222.

[18] Nwokoye, D. N., Influence of Binary Aggregate Proportions Upon Some Concrete Properties," Magazine of Concrete Research, Vol. 27, No. 9, Dec. 1975, pp. 229238.

[19] ASTM C33-90, Standard Specification for Concrete Aggregates," Annual Book of Standards, ASTM, Philadelphia, Vol. 04.02, 1990.

[20] "Standard Specifications, "Indiana Department of Highways, 1988, pp. 500-505.

[21] Hughes, B. P., "Rational Concrete Mix Design," Proceedings Institution of Civil Engineering, Vol. 17, 1960. pp. 315-332.

[22] Furnas, C. C., "Grading Aggregates: Mathematical Relations for Beds of Broken Solids of Maximum Density," Ind. and Eng. Chem., Vol. 23, 1931, pp. 10521058.

[23] Lees, G., "Rational Design of Continuous and Intermittent Aggregate Gradings for Concrete," Highway Research Record 441, Transportation Research Board, Washington, D. C., 1973, pp.-16.

[24] Popovics, S., "Aggregate Grading and the Internal Structure of Concrete," Highway Research Record 441, Transportation Research Board, Washington, D. C., 1973, pp. 56-64.

[25] Ehrenburg, D. O., "An Analytical Approach to Gap-Graded Concrete," Cement, Concrete, and Aggregates, Vol. 2, No. 1, Summer 1980, pp. 39-42.

[26] Li, S., and Ramakrishnan, V.. "Gap-Graded Aggregates for High Strength Quality Concrete," Highway Research Record 441, Transportation Research Board, Washington, D. C., 1973, pp. 17-32.

[27] Shilstone, J. M., "Concrete Mixture Optimization" Concrete International, American Concrete Institute, Jun. 1990, pp. 33-39.

[28] Mindess, S., and Young, J. F., "Concrete," Prentice Hall, Englewood Cliffs, NJ, 1981.

[29] Dodson, V., "Concrete Admixtures," Van Nostrand Reinhold, New York, 1990, pp. 137-151. 
[30] Powers, T. C., "The Air Requirements for Frost Resistant Concrete," Proceedings Highway Research Board 29;184, 1949.

[31] Atkins, H. N., "Highway Materials, Soils, and Concretes," Reston, Reston. VA. 1983.

[32] Hollon, G. W., and Prior, M. E., "Factors Influencing Proportioning of AirEntrained Concrete,' ACI SP-46. Proportioning Concrete Mixes, American Concrete Institute, Detroit, MI., 1974, pp. 11-23.

[33] Neville, A "Properties of Concrete," Pitman, London, 1981.

[34] Rixom, M.R., "Chemical Admixtures for Concrete," E. \& F. N. Spon, London, 1986, pp. 111-121.

[35] Dolch, W. L., "Air Entraining Admixtures," Concrete Admixture Handbook, Noyes, Park Ridge, NJ., 1984, pp. 269-302.

[36] Mill Analysis of Cement, Purdue Laboratory Cement 329, Lonestar Industries, INC., Greencastle, IN., Dec. 1991.

[37] Construction Records for INDOT Contract R-17986, Rieth-Riley Construction, Goshen, IN., 1992.

[38] Construction Records for INDOT Contract R-19794, Rieth-Riley Construction, Goshen, IN., 1992.

[39] Yield, Slump, and Air Content Reports for INDOT Contract R-19394, Indiana - Department of Transportation, Div. of Materials, Indianapolis, IN., 1992.

[40] Construction Records for INDOT Contract R-19515, Rieth-Riley Construction, Goshen, IN., 1992.

[41] Construction Records for Old Cleveland Road project City of South Bend, RiethRiley Construction, Goshen, IN, 1992.

[42] Olek, J., "Properties of Fly Ash Concrete," Ph.D. Thesis, Purdue University , West Lafayette, IN, 1991.

[43] ASTM C127-88, "Standard Test Method for Specific Gravity and Absorption of Coarse Aggregate," Annual Book of Standards, ASTM, Philadelphia, Vol. 04.02. 1990.

[44] ASTM C 128-88, "Standard Test Method for Specific Gravity and Absorption of Fine Aggregate," Annual Book of Standards, ASTM, Philadelphia, Vol. 04.02, 1990.

[45] ASTM C136-84, "Standard Test Method for Sieve Analysis of Fine and Coarse Aggregates," Annual Book of Standards, ASTM, Philadelphia, Vol. 04.02, 1990. 
[46] ASTM C192-81, "Standard Method of Making and Curing Concrete Test Specimens in the Laboratory," Annual Book of Standards, ASTM. Philadelphia. Vol. 04.02, 1990.

[47] ASTM C143-78, "Standard Test Method for Slump of Portland Cement Concrete," Annual Book of Standards, ASTM, Philadelphia, Vol. 04.02, 1990.

[48] ASTM C138-81, "Standard Test Method for Unit Weight, Yield, and Air Content (Gravimetric) of Concrete," Annual Book of Standards, ASTM, Philadelphia, Vol. 04.02, 1990.

[49] ASTM C231-82, "Standard Test Method for Air Content of Freshly Mixed Concrete by the Pressure Method," Annual Book of Standards. ASTM. Philadelphia, Vol. 04.02, 1990.

[50] ASTM C78-84, "Standard Test Method for Flexural Strength of Concrete (Using Simple Beam with Third Point Loading)," Annual Book of Standards, ASTM, Philadelphia, Vol. 04.02, 1990.

[51] ASTM C457-88, "Standard Practice for Microscopical Determination of the AirVoid System in Hardened Concrete," Annual Book of Standards, ASTM, Philadelphia, Vol. 04.02, 1990.

[52] ACI Standard 116R-78, "Cement and Concrete Terminology." American Concrete Institute, 1982, pg. 3. 

